\title{
Real Coded Genetic Algorithm Operators Embedded in Gravitational Search Algorithm for Continuous Optimization
}

\author{
Amarjeet Singh \\ Department of Mathematics, Indian Institute of Technology Roorkee, Roorkee - 247667, Uttarakhand, India. \\ Emails: amarjeetiitr@gmail.com \\ Kusum Deep \\ Department of Mathematics, Indian Institute of Technology Roorkee, Roorkee - 247667, Uttarakhand, India. \\ Emails: kusumdeep@gmail.com
}

\begin{abstract}
The objective of this paper is to propose three modified versions of the Gravitational Search Algorithm for continuous optimization problems. Although the Gravitational Search Algorithm is a recently introduced promising memory-less heuristic but its performance is not so satisfactory in multimodal problems particularly during the later iterations. With a view to improve the exploration and exploitation capabilities of GSA, it is hybridized with well-known real coded genetic algorithm operators. The first version is the hybridization of GSA with Laplace Crossover which was initially designed for real coded genetic algorithms. The second version is the hybridization of GSA with Power Mutation which also was initially designed for real coded genetic algorithms. The third version hybridizes the GSA with both the Laplace Crossover and the Power mutation. The performance of the original GSA and the three proposed variants is investigated over a set of 23 benchmark problems considered in the original paper of GSA. Next, all the four variants are implemented on 30 rotated and shifted benchmark problems of CEC 2014. The extensive numerical, graphical and statistical analysis of the results show that the third version incorporating the Laplace Crossover and Power mutation is a definite improvement over the other variants.
\end{abstract}

Index Terms-Gravitational Search Algorithm, Real Coded Genetic Algorithm operators, Laplace Crossover, Power Mutation, continuous optimization.

\section{INTRODUCTION}

Many real-world nonlinear optimization problems are possessing increased level of complexities. Their nature may be highly non-linear or high dimensional or nondifferential discontinuous or having large search space or their search space may increase exponentially with problem size. Although in literature many deterministic techniques are available but they are applicable to a restricted class of functions e.g. Lipchitz continuous functions, differentiable functions etc. On the other hand, probabilistic techniques are becoming increasingly popular due to their ease of use and wide applicability. Due to the No Free Lunch Theorem no single algorithm can solve problems of all complexities. Therefore, efficient and reliable optimization algorithms are always in demand. In the last few decades, more adaptable and flexible heuristic optimization algorithms have been developed to handle such problems, especially with imperfect or incomplete information. Deriving their inspiration from natural phenomenon like evolutionary process of living organisms and swarm behaviour, Nature Inspired Algorithms are one such category of popular algorithms which find numerous applications in clustering, pattern recognition, image processing, numerical and combinatorial optimization and many other problems arising in science, engineering, business, economics and finance.

Ant Colony Optimization (ACO) [1], Artificial Bee Colony (ABC) [2], Artificial Immune System (AIS) [3], Bacterial Foraging Optimization Algorithm (BFOA) [4], Differential Evolution (DE) [5], Genetic Algorithm (GA) [6], Glowworm Swarm Optimization (GSO) [7,8], Particle Swarm Optimization (PSO) [9] are some of the biological-based stochastic nature inspired optimization algorithm. Simulated Annealing (SA) [10], Artificial Physics Optimization (APO) [11, 12], Central Force Optimization (CFO) [13], Harmony Search Algorithm (HS) [14], Space Gravitation optimization [15] etc. are physics inspired heuristic search algorithms [16]. These algorithms mimic physical behaviour and physical principals.

To achieve efficient global and local search, a heuristic algorithm must have a good trade-off between exploration and exploitation. The exploration ability makes the algorithm to investigate the search space and explore new and better solutions, and exploitation ability make the algorithm to search the optimal solution near a good one. The ability of exploration and exploitation of heuristic algorithm is made by specific operators. Hence, new operators are designed or available operators are redesigned in order to add specific capabilities in heuristic algorithms to solve such problems. 
Recently, a new physics based heuristic optimization algorithm, namely Gravitational Search Algorithm (GSA) has been introduced by Rashedi et al [17]. It mimics the characteristic of Newton's law of gravitation and motion. GSA is popular as it has a small number of parameter to adjust and it is easy to implement. But like other heuristics GSA too has some demerits. It is not suitable for highly complex problems. It usually get stuck at local optimal solutions or non-optimal solutions, therefore it is unable to improve the quality of solutions in the latter iterations. To overcome these drawbacks many researchers have introduced new operator in it and also hybridized with other heuristic algorithms.

Sarafrazi et al [18] defined a new operator "Disruption", originating from astrophysics and Doraghinejad et al [19] defined a new operator "Black Hole", inspired by some of the characteristics of the black hole as an astronomy phenomenon, for GSA to increase the exploration and exploitation ability. Based on the dynamics of Quantum, Mohadeseh Soleimanpour et al [20] proposed Quantum behaved GSA but it suffers with diversity loss problem in collecting the masses of objects. Later on, Improved Quantum behaved GSA is proposed in which fitness function of QGSA is replaced by new fitness function [21, 22]. Radu et al [23, 24] applied three modifications: define constraint regarding system, modify deprecation equation of gravitation constant and extended symmetrical method and proposed new GSA to reduce parametric sensitivity of fuzzy based control system for optimal tuning. Gao et al [25] proposed a chaotic GSA which combines GSA with chaos. Rashedi et al. [26] proposed Binary GSA for solving discrete optimization problems. Mirjalili et al [27] proposed PSOGSA in which particles update their velocity using PSO velocity update equation. Chengyi [28] proposed Simulated Annealing based GSA in which position of the particles updated according to Metropolis-principle. Xu et al [29] proposed Improved GSA which uses trial-and-error method to update the optimal agent during the whole search process. GSA is memory less algorithm. Hence, for enhancing particle memory ability and improve its search accuracy, $\mathrm{Gu}$ et al [30] uses the idea of local optimum solution and global optimum solution from PSO and proposed modified GSA. Jiang et al [31] proposed an improved GSA, in which the chaos operator and memory strategy are applied.

GSA has also been successfully applied to solve constrained as well as multi-objective optimization problems. Yadav et al [32] used GSA to solve constrained optimization problems and [33] also hybridized it with Differential Evolution. Nobahari et al [34] extend GSA and proposed non-dominated sorting GSA for multi-objective optimization problems. Hassanzadeh et al [35] also proposed another variant for multi-objective problems. It used pareto optimality function with standard GSA.

In this paper, an attempt is made to hybridize GSA with well-known real coded crossover operators. Three versions are proposed. First, GSA is hybridized with Laplace Crossover (LX) Operator, second GSA is hybridized with Power Mutation (PM) Operator and thirdly it is hybridized with both LX and PM. The motivation behind this hybridization is that the exploration and exploitation capabilities of GSA can be enhanced by the LX and PM operators of Real Coded Genetic Algorithms.

The remaining paper is composed as follows: In section II, the Gravitational Search Algorithm is explained. In section III, the three proposed versions of GSA are described. In section IV, the numerical results are analysed. In section $\mathrm{V}$, the performance of the four algorithms is demonstrated on the rotated and shifted benchmark collection as given in CEC 2014. Finally in section VI the conclusions are drawn.

\section{GRavitational SEARCh Algorithm}

Gravitational Search Algorithm (GSA) is a new addition in the class of nature inspired optimization techniques based on gravitational interaction between masses [17]. GSA artificially simulates the Newton's Theory, Newtonian laws of gravitation and motion. Newton's law of gravity states that every particle attracts other particle by means of some gravitational force and the gravitational force between two particles is directly proportional to the product of their masses and inversely proportional to the square of the distance between them. Law of motion states that the current velocity of any mass is equal to the sum of the fraction of its previous velocity and the variation in the velocity. Variation in the velocity or acceleration of any mass is equal to the force acted on the system divided by mass of inertia.

In GSA, agents are considered as particles and every particles represent a candidate solution. Their fitness is measured by their masses, heavy masses correspond to good solution. Due to gravitational force, these particles attract each other and moves towards the heavy mass objects. Hence, gravitational force guide the masses. Heavy masses move slowly than lighter masses (exploitation).

The continuous nonlinear optimization problem is defined as:

$$
\text { Minimize } f(x)
$$

Subject to

$$
x^{\text {lower }} \leq x \leq x^{\text {upper }}
$$

Consider a system of $\mathrm{N}$ particles and the position of particle $i$ is represented as:

$$
x_{i}=\left(x_{i}^{1}, x_{i}^{2}, \ldots, x_{i}^{d}, \ldots x_{i}^{m}\right) \text { for } i=1,2, \ldots, N
$$

where $x_{i}^{d}$ is the position of particle $i$ in dimension $d$. the total force of attraction exerted by the $\mathrm{i}^{\text {th }}$ particle at time $\mathrm{t}$ in $\mathrm{d}$ dimension is given by Eq. (3) 
$F_{i}^{d}(t)=\sum_{j \in k b e s t, y \neq i} \operatorname{rand}_{j} G(t) \frac{M_{p i}(t) M_{a j}(t)}{R_{i j}(t)+\varepsilon}\left(x_{j}^{d}(t)-\mathcal{X}_{i}^{d}(t)\right.$



Fig.1. Pseudo code of GSA

Where rand $_{j}$ is a random number in the interval [0, 1], $M_{p i}(t)$ is the passive gravitation mass related to $i^{\text {th }}$ particle mass at time t, $M_{a j}(t)$ is the active gravitational mass related to $\mathrm{j}^{\text {th }}$ particle at time $\mathrm{t}, R_{i j}(t)$ is Euclidean distance between particles $i$ and $\mathrm{j}, \varepsilon$ is a small constant, kbest $_{j}$ is the set of first $\mathrm{K}$ particles arranged in decreasing order according to their fitness. $G(t)$ is the gravitational constant at time $\mathrm{t}$ and the value of $G(t)$ is calculated by

$$
G(t)=G_{0} \exp (-a t / \text { max_iter })
$$

Here, $\alpha$ is a constant and $G_{0}$ is initial value.

The gravitational mass and inertia mass for each particle are calculated as follows

$$
M_{p i}(t)=M_{a i}(t)=M_{i i}(t)=M_{i}(t)
$$

$$
m_{i}(t)=\frac{f\left(x_{i}(t)\right)-\operatorname{worst}(t)}{\operatorname{best}(t)-\operatorname{worst}(t)}, i=1,2, \ldots, N
$$

$$
M_{i}(t)=m_{i}(t) / \sum_{j=1}^{N} m_{j}(t)
$$

where $f\left(x_{i}(t)\right)$ is the fitness of $i^{\text {th }}$ particle at time t. The acceleration of particle $i$ in dimension $\mathrm{d}$ at a specific time $\mathrm{t}$ is

$$
a_{i}^{d}(t)=\frac{F_{i}^{d}(t)}{M_{i i}(t)}
$$

The next velocity of a particle $i$ is a fraction of its current velocity added to its acceleration.

$$
v_{i}^{d}(t+1)=\operatorname{rand} v_{i}^{d}(t)+a_{i}^{d}(t)
$$

The next position of particle $i$ is updated by

$$
x_{i}^{d}(t+1)=x_{i}^{d}(t)+v_{i}^{d}(t+1)
$$

In the initial population, a particle having best fitness value is set to Lbest and in successive iteration the fitness of Lbest is compared with the best particle's fitness in each iteration, if it has better fitness than Lbest is updated otherwise Lbest remains same. Fig. 1 show the pseudo code of GSA.

\section{ThreE PROPOSED HyBRID Versions OF GSA}

In the present study, an effort is made to enhance the exploration and exploitation ability of GSA by hybridizing it with two well-known operators of Real Coded Genetic Algorithms, namely Laplace Crossover and Power Mutation. First these two operators are explained below.

\section{A. Laplace Crossover}

Laplace Crossover (LX) is introduced by Deep and Thakur [36] based on Laplace distribution. It generates a pair of offspring $y_{1}=\left(y_{1}^{1}, y_{1}^{2}, \ldots, y_{1}^{m}\right)$ and $y_{2}=\left(y_{2}^{1}, y_{2}^{2}, \ldots, y_{2}^{m}\right)$ from a pair of parents $x_{1}=\left(x_{1}^{1}, x_{1}^{2}, \ldots, x_{1}^{m}\right)$ and $x_{2}=\left(x_{2}^{1}, x_{2}^{2}, \ldots, x_{2}^{m}\right)$ in the following way. First, two uniformly distributed random numbers $r_{i}, s_{i} \in[0,1]$ are generated and a random number $\beta_{i}$, following Laplace distribution, is generated as:

$$
\beta_{i}= \begin{cases}a-b \log _{e}\left(r_{i}\right), & s_{i} \leq 0.5 \\ a+b \log _{e}\left(r_{i}\right), & s_{i}>0.5\end{cases}
$$

Then offspring are created by the equations: 


$$
\begin{aligned}
& y_{1}^{i}=x_{1}^{i}+\beta_{i}\left|x_{1}^{i}-x_{2}^{i}\right|, \\
& y_{2}^{i}=x_{2}^{i}+\beta_{i}\left|x_{1}^{i}-x_{2}^{i}\right|,
\end{aligned}
$$

Let $x_{\text {lower }}^{i}$ and $x_{\text {upper }}^{i}$ to be the lower and upper bounds of the unknown variables $x^{i}$. If $x^{i}<x_{\text {lower }}^{i}$ or $x^{i}>x_{\text {upper }}^{i}$ for some $i$, then $x^{i}$ is assigned a random value in the interval $\left[x_{\text {lower }}^{i}, x_{\text {upper }}^{i}\right]$.

\section{B. Power Mutation}

Power Mutation (PM) operator introduced by Deep and Thakur [37] based on power distribution. PM operator creates a solution $y$ in the vicinity of a parent solution $\bar{x}$ in the following manner. First, a uniformly distributed random number $r \in[0,1]$ is generated. Then a random number $w$ following power distribution, is generated by $w=r^{1 / p}$, where $\mathrm{p}$ is the index of distribution. Offspring $y$ is created by the formula:

$$
y=\left\{\begin{array}{l}
\bar{x}-w\left(\bar{x}-x_{\text {lower }}\right), \text { if } t<v \\
\bar{x}+w\left(x_{\text {upper }}-\bar{x}\right), \text { if } t \geq v
\end{array}\right.
$$

Where $v \in[0,1]$ is a uniformly distributed random number, $t=\frac{\bar{x}-x_{\text {lower }}}{x_{\text {upper }}-x_{\text {lower }}}$ and $x_{\text {lower }}$ and $x_{\text {upper }}$ are lower and upper bound of decision variables. For small value of $\mathrm{p}$, it achieves less perturbation and for large value of $\mathrm{p}$, it achieves more diversity in the solution.

The hybridization of GSA is performed with the above defined Laplace Crossover, which is a real coded crossover operator for real coded genetic algorithm and the above defined power mutation, which is a real coded mutation operator for real coded genetic algorithm. The motivation behind this hybridization is that the mass of particles may decrease with the passage of time due to environment change. Hence, the exploration and exploitation of GSA may improve with the implementation of real coded genetic algorithm operators. With a view to enhance the performance of GSA, the following three proposed variants of GSA are designed.

\section{Proposed LX-GSA}

After the completion of each iteration of GSA, the Lbest particle and a randomly selected particle are selected as parents and Laplace crossover is applied to produce two offsprings called $y_{1}$ and $y_{2}$. If fitness of $y_{1}$ is better than the fitness of worst particle then, worst is replaced by $y_{1}$ and worst is updated. In either case, if fitness of $y_{2}$ is better than the fitness of worst then, worst is replaced by $y_{2}$ and Lbest is updated if offsprings have better fitness. Then the iteration is incremented. Fig. 2 shows the pseudo code of LX-GSA.

\section{Proposed PM-GSA}

After the completion of each iteration of GSA, the Lbest particle is selected and the Power Mutation is applied to produce a mutated offspring called $y$. If fitness of $y$ is better than the fitness of worst, then worst is replaced by $y$ and Lbest is updated if offspring has better fitness. Then the iteration is incremented. Fig. 3 shows the pseudo code of PM-GSA.

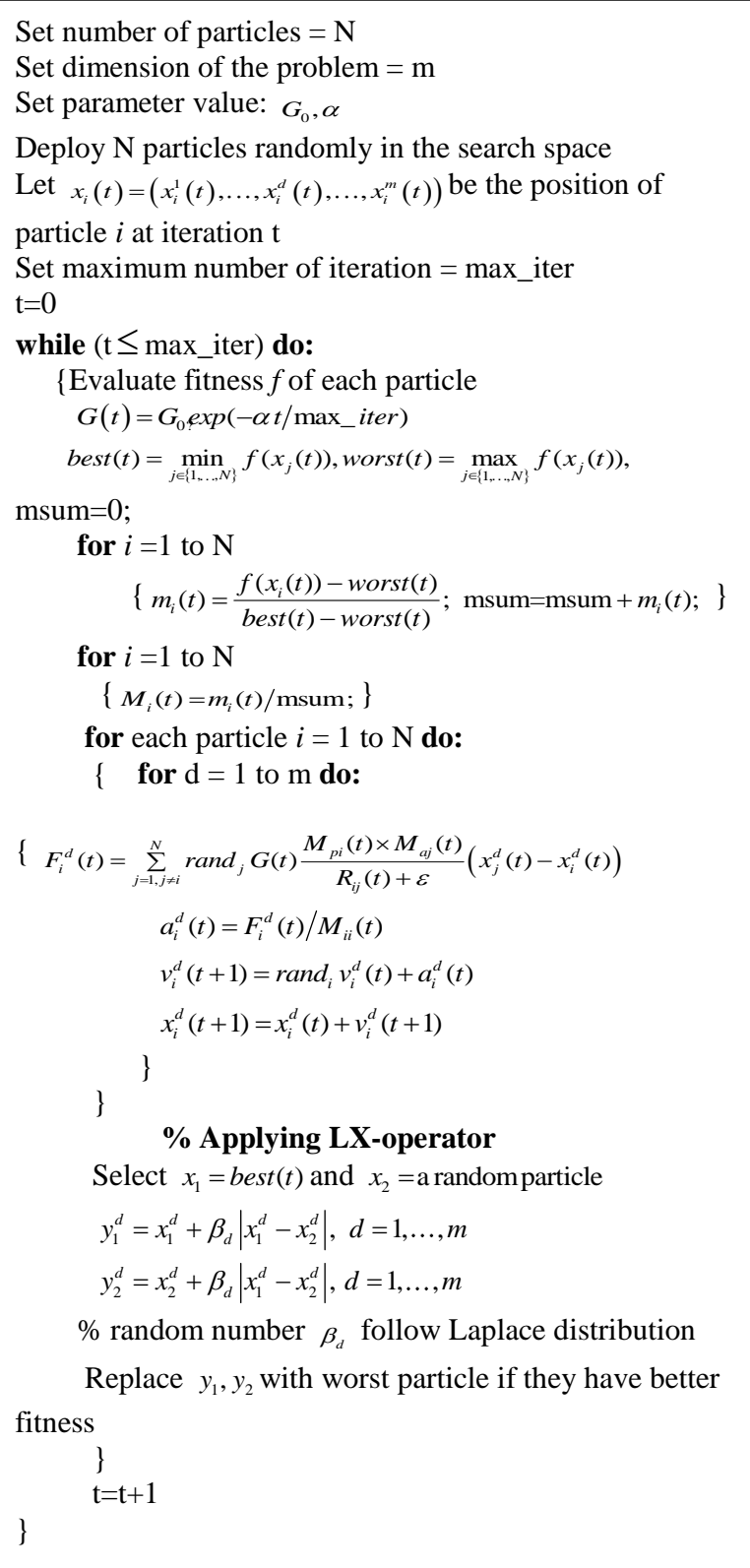

Fig.2. Pseudo code of LX-GSA 
Set number of particles $=\mathrm{N}$

Set dimension of the problem $=\mathrm{m}$

Set parameter value: $G_{0}, \alpha$

Deploy $\mathrm{N}$ particles randomly in the search space

Let $x_{i}(t)=\left(x_{i}^{1}(t), \ldots, x_{i}^{d}(t), \ldots, x_{i}^{m}(t)\right)$ be the position of

particle $i$ at iteration t

Set maximum number of iteration $=$ max_iter

$\mathrm{t}=0$

while $\left(\mathrm{t} \leq \mathrm{max} \_\right.$iter $)$do:

\{Evaluate fitness $f$ of each particle

$G(t)=G_{0} \exp \left(-\alpha t / \max _{-}\right.$iter $)$

$\operatorname{best}(t)=\min _{j \in\{1, \ldots, N\}} f\left(x_{j}(t)\right)$, worst $(t)=\max _{j \in\{1, \ldots, N\}} f\left(x_{j}(t)\right)$,

msum $=0$;

for $i=1$ to $\mathrm{N}$

$$
\left\{m_{i}(t)=\frac{f\left(x_{i}(t)\right)-\operatorname{worst}(t)}{\operatorname{best}(t)-\operatorname{worst}(t)} ; \operatorname{msum}=\mathrm{msum}+m_{i}(t) ;\right\}
$$

for $i=1$ to $\mathrm{N}$

$\left\{M_{i}(t)=m_{i}(t) / \mathrm{msum} ;\right\}$

for $i=1$ to $\mathrm{N}$ do:

$\{$ for $d=1$ to $m$ do:

$\left\{F_{i}^{d}(t)=\sum_{j \in k b e s t, j \neq i} \operatorname{rand}_{j} G(t) \frac{M_{p i}(t) \times M_{a j}(t)}{R_{i j}(t)+\varepsilon}\left(x_{j}^{d}(t)-x_{i}^{d}(t)\right)\right.$

$a_{i}^{d}(t)=F_{i}^{d}(t) / M_{i i}(t)$

$v_{i}^{d}(t+1)=\operatorname{rand}_{i} v_{i}^{d}(t)+a_{i}^{d}(t)$

$x_{i}^{d}(t+1)=x_{i}^{d}(t)+v_{i}^{d}(t+1)$

$$
\}
$$

\}

\section{\% Applying Power Mutation}

Select $\bar{x}=\operatorname{best}(t)$

$y^{d}=\left\{\begin{array}{l}\bar{x}^{d}-w_{d}\left(\bar{x}^{d}-x_{\text {lower }}^{d}\right), \text { if } t_{d}<v_{d} \\ \bar{x}^{d}+w_{d}\left(x_{\text {upper }}^{d}-\bar{x}^{d}\right), \text { if } t_{d} \geq v_{d}\end{array} \quad d=1, \ldots, m\right.$

$\% w_{d}$ is a random number follow power distribution,

$v_{d}$ is a uniformly distributed random number and

$t_{d}=\frac{\bar{x}^{d}-x_{\text {lower }}^{d}}{x_{\text {upper }}^{d}-x_{\text {lower }}^{d}}, x_{\text {lower }}^{d}$ and $x_{\text {upper }}^{d}$ are lower and upper

bound of $i^{\text {th }}$ variable

Replace $y$ with worst particle if it has better fitness

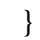

$\mathrm{t}=\mathrm{t}+1$

\}

Fig.3. Pseudo code PM-GSA

\section{E. Proposed LX-PM-GSA}

After the completion of each iteration of GSA, the Lbest particle and a randomly selected particle are selected as parents and Laplace crossover is applied to produce two offsprings called $y_{1}$ and $y_{2}$. If fitness of $y_{1}$ is better than the fitness of worst then, worst is replaced by $y_{1}$ and worst is updated. In either case, if fitness of $y_{2}$ is better than the fitness of worst then, worst is replaced by $y_{2}$ and Lbest is updated if offsprings have better fitness.

Then, Lbest particle is selected and the Power Mutation is applied to produce a mutated offspring called $y$. If fitness of $y$ is better than the fitness of worst, then worst is replaced by $y$ and Lbest is updated if offspring has better fitness. Then the iteration is incremented. Fig. 4 shows the pseudo code of LX-PMGSA.

\section{Set number of particle $=\mathrm{N}$}

Set dimension of the problems $=\mathrm{m}$

Set parameter value: $G_{0}, \alpha$

Deploy $\mathrm{N}$ particles randomly in the search space

Let $x_{i}(t)=\left(x_{i}^{1}(t), \ldots, x_{i}^{d}(t), \ldots, x_{i}^{m}(t)\right)$ be the position of

particle $i$ at iteration $\mathrm{t}$

Set maximum number of iteration $=$ max $\_$iter

$\mathrm{t}=0$

while $(\mathrm{t} \leq$ max_iter) do:

\{Evaluate fitness $f$ of each particle

$G(t)=G_{0} \exp \left(-\alpha t / \mathrm{max} \_\right.$iter $)$

$\operatorname{best}(t)=\min _{j \in\{1 \ldots \ldots\}} f\left(x_{j}(t)\right)$, worst $(t)=\max _{j \in\left\{1 \ldots N^{\prime}\right\}} f\left(x_{j}(t)\right)$,

msum $=0$;

for $i=1$ to $\mathrm{N}$

$$
\left\{m_{i}(t)=\frac{f\left(x_{i}(t)\right)-\operatorname{worst}(t)}{\operatorname{best}(t)-\operatorname{worst}(t)} ; \operatorname{msum}=\mathrm{msum}+m_{i}(t) ;\right\}
$$

for $i=1$ to $\mathrm{N}$

$\left\{M_{i}(t)=m_{i}(t) / \mathrm{msum} ;\right\}$

for each particle $i=1$ to $\mathrm{N}$ do:

$\{$ for $d=1$ to $m$ do:

$\left\{F_{i}^{d}(t)=\sum_{j \in k b s t, j \neq i} \operatorname{rand}_{j} G(t) \frac{M_{p i}(t) \times M_{a j}(t)}{R_{i j}(t)+\varepsilon}\left(x_{j}^{d}(t)-x_{i}^{d}(t)\right)\right.$

$a_{i}^{d}(t)=F_{i}^{d}(t) / M_{i i}(t)$

$v_{i}^{d}(t+1)=\operatorname{rand}_{i} v_{i}^{d}(t)+a_{i}^{d}(t)$

$x_{i}^{d}(t+1)=x_{i}^{d}(t)+v_{i}^{d}(t+1)$

$$
\}
$$

\% Applying LX-operator

Select $x_{1}=\operatorname{best}(t)$ and $x_{2}=$ a random particle

$$
y_{1}^{d}=x_{1}^{d}+\beta_{d}\left|x_{1}^{d}-x_{2}^{d}\right|, d=1, \ldots, m
$$$$
y_{2}^{d}=x_{2}^{d}+\beta_{d}\left|x_{1}^{d}-x_{2}^{d}\right|, d=1, \ldots, m
$$

$\%$ random number $\beta_{d}$ follow Laplace distribution

Replace $y_{1}, y_{2}$ with worst particle if they have better fitness

\section{\% Applying Power Mutation}

Select $\bar{x}=$ best $(t)$

$y^{d}=\left\{\begin{array}{l}\bar{x}^{d}-w_{d}\left(\bar{x}^{d}-x_{\text {lower }}^{d}\right), \text { if } t_{d}<v_{d} \\ \bar{x}^{d}+w_{d}\left(x_{\text {upper }}^{d}-\bar{x}^{d}\right), \text { if } t_{d} \geq v_{d}\end{array} \quad d=1, \ldots, m\right.$

$\% w_{d}$ is a random number follow power distribution,

$v_{d}$ is a uniformly distributed random number and

$t_{d}=\frac{\bar{x}^{d}-x_{\text {lower }}^{d}}{x_{\text {upper }}^{d}-x_{\text {lower }}^{d}}, x_{\text {lower }}^{d}$ and $x_{\text {upper }}^{d}$ are lower and upper bound of $i^{\text {th }}$ variable

Replace $y$ with worst particle if it has better fitness \}

$\mathrm{t}=\mathrm{t}+1$

Fig.4. Pseudo code of LX-PM-GSA 


\section{BENCHMARK FUNCTIONS AND EXPERIMENTAL RESULTS}

To test the performance of proposed versions of GSA, the same set of 23 benchmark function are selected as considered in the first paper of GSA [17] and reproduced in the APPENDIX A of this paper. This set consists unimodal, multimodal, low dimensional and high dimensional functions. Functions $F_{1}$ to $F_{7}$ are high dimensional unimodal functions, $F_{8}$ to $F_{13}$ are high dimensional multimodal functions and $F_{14}$ to $F_{23}$ are low dimensional multimodal functions with fixed dimension. Environment for running the experiments is processor: Intel (R) Xeon (R) CPU @ 2.80GHz, RAM: 144.00 GB, operating system: Window 7, Integrated Development Environment: Matlab 2010. The parameters of the algorithm are $G_{0}=100, \alpha=20, p=0.25, a=0, b=0.35$ and population size $=50$. To test the performance of the algorithms, three experiments are performed. In experiment $\mathrm{I}$, the termination criteria is: maximum iterations $=4000$ for the function $F_{1}$ to $F_{13}$ and maximum iterations $=2000$ for $F_{14}$ to $F_{23}$. The GSA, LX-GSA, PMGSA and LX-PM-GSA are run 30 times each. In experiment II, the termination criteria is: maximum iterations $=4000$ and absolutely error is less than 0.01 for the function $F_{1}$ to $F_{13}$ and maximum iterations $=2000$ and absolutely error less than 0.01 for $F_{14}$ to $F_{23}$, where absolute error is defined as the absolute difference between the known objective function value and the obtained objective function value by the algorithms. The GSA, LX-GSA, PM-GSA and LX-PM-GSA are run 50 times each. A run is considered to be a success if best objective function value in the population has error less than 0.01 within above defined iterations. In experiment III, algorithms are used to solve CEC2014 test problems. For a fair comparison among the algorithms the first randomly generated population is used for the first run of all algorithm, second randomly generated population is used for second run of all algorithm, and so on.

\section{A. Analysis of Results based on Experiment I}

Following the same performance measures as considered in the first paper of GSA [17], the Average best-so-far, Median best-so-far, Average mean fitness, Best, Worst, standard deviation of the objective function values of function $F_{1}$ to $F_{7}$ are shown in Table 1, for $F_{8}$ to $F_{13}$ are shown in Table 2, for $F_{14}$ to $F_{23}$ are shown in Table 3. The best entries are highlighted in bold in each of the Table 1, 2 and 3.

Table 1. Objective Function Values for High Dimensional Unimodal Functions

\begin{tabular}{|c|c|c|c|c|c|c|c|c|}
\hline Pro. & D. & Algorithm & $\begin{array}{c}\text { Average } \\
\text { best so far }\end{array}$ & $\begin{array}{l}\text { Median } \\
\text { best so far }\end{array}$ & $\begin{array}{c}\text { Average } \\
\text { mean } \\
\text { fitness } \\
\end{array}$ & Best & Worse & STD \\
\hline \multirow[t]{4}{*}{$F_{1}$} & 30 & GSA & $2.79 \mathrm{E}-18$ & $2.92 \mathrm{E}-18$ & $9.77 \mathrm{E}-18$ & $1.16 \mathrm{E}-18$ & $5.16 \mathrm{E}-18$ & $9.78 \mathrm{E}-19$ \\
\hline & & LX-GSA & $1.85 E-18$ & 1.91E-18 & 8.37E-18 & 8.59E-19 & $2.76 \mathrm{E}-18$ & $5.54 \mathrm{E}-19$ \\
\hline & & PM-GSA & $2.94 \mathrm{E}-18$ & $2.84 \mathrm{E}-18$ & $1.01 \mathrm{E}-17$ & 1.79E-18 & $4.38 \mathrm{E}-18$ & $6.62 \mathrm{E}-19$ \\
\hline & & LX-PM-GSA & $2.09 \mathrm{E}-18$ & $2.1 \mathrm{E}-18$ & $8.45 \mathrm{E}-18$ & 1.33E-18 & $3.11 \mathrm{E}-18$ & 3.8E-19 \\
\hline \multirow[t]{4}{*}{$\mathrm{F}_{2}$} & 30 & GSA & $7.66 \mathrm{E}-09$ & $7.35 \mathrm{E}-09$ & $1.34 \mathrm{E}-08$ & $5.36 \mathrm{E}-09$ & $1.06 \mathrm{E}-08$ & $1.44 \mathrm{E}-09$ \\
\hline & & LX-GSA & 5.97E-09 & 5.79E-09 & $1.2 \mathrm{E}-08$ & 3.66E-09 & 7.85E-09 & 1.01E-09 \\
\hline & & PM-GSA & $7.79 \mathrm{E}-09$ & 7.44E-09 & $1.34 \mathrm{E}-08$ & $5.32 \mathrm{E}-09$ & $1.27 \mathrm{E}-08$ & $1.67 \mathrm{E}-09$ \\
\hline & & LX-PM-GSA & 5.72E-09 & 5.59E-09 & 1.16E-08 & 3.77E-09 & $9.06 \mathrm{E}-09$ & $1.11 \mathrm{E}-09$ \\
\hline \multirow[t]{4}{*}{$F_{3}$} & 30 & GSA & 3.217619 & 2.005779 & 3.217619 & 0.268354 & 11.72383 & 3.264068 \\
\hline & & LX-GSA & 0.001277 & $3.5 \mathrm{E}-17$ & 0.001278 & $1.49 \mathrm{E}-17$ & 0.016613 & 0.003443 \\
\hline & & PM-GSA & 3.254921 & 2.602324 & 3.254921 & 0.245432 & 10.32525 & 2.622834 \\
\hline & & LX-PM-GSA & $9.28 \mathrm{E}-05$ & 3.46E-17 & $9.3 E-05$ & 1.06E-17 & 0.000898 & 0.000248 \\
\hline \multirow[t]{4}{*}{$\mathrm{F}_{4}$} & 30 & GSA & $1.65 \mathrm{E}-09$ & $1.65 \mathrm{E}-09$ & $2.49 \mathrm{E}-09$ & 1.14E-09 & $2.36 \mathrm{E}-09$ & $2.79 \mathrm{E}-10$ \\
\hline & & LX-GSA & $1.23 \mathrm{E}-09$ & $1.23 \mathrm{E}-09$ & $2.1 \mathrm{E}-09$ & 9.2E-10 & $1.67 \mathrm{E}-09$ & $1.98 \mathrm{E}-10$ \\
\hline & & PM-GSA & $1.56 \mathrm{E}-09$ & $1.58 \mathrm{E}-09$ & $2.31 \mathrm{E}-09$ & $9.53 \mathrm{E}-10$ & $2.5 \mathrm{E}-09$ & $3.35 \mathrm{E}-10$ \\
\hline & & LX-PM-GSA & 1.19E-09 & $1.16 \mathrm{E}-09$ & $2.09 \mathrm{E}-09$ & $6.82 \mathrm{E}-10$ & $1.7 \mathrm{E}-09$ & $2.56 \mathrm{E}-10$ \\
\hline \multirow[t]{4}{*}{$\mathrm{F}_{5}$} & 30 & GSA & 21.7292 & 21.7113 & 21.7292 & 21.25285 & 22.24311 & 0.25062 \\
\hline & & LX-GSA & 20.52656 & 20.5155 & 20.52668 & 20.1799 & 20.8962 & 0.176059 \\
\hline & & PM-GSA & 23.57698 & 21.69065 & 23.57698 & 21.27451 & 78.65698 & 10.40432 \\
\hline & & LX-PM-GSA & 20.75712 & 20.56332 & 20.75742 & 20.18272 & 26.30862 & 1.067888 \\
\hline \multirow[t]{4}{*}{$\mathrm{F}_{6}$} & 30 & GSA & 0 & 0 & 0 & 0 & 0 & 0 \\
\hline & & LX-GSA & 0 & 0 & 0 & 0 & 0 & 0 \\
\hline & & PM-GSA & 0 & 0 & 0 & 0 & 0 & 0 \\
\hline & & LX-PM-GSA & 0 & 0 & 0 & 0 & 0 & 0 \\
\hline \multirow[t]{4}{*}{$\mathrm{F}_{7}$} & 30 & GSA & 0.014339 & 0.013506 & 0.571078 & 0.008935 & 0.026754 & 0.00419 \\
\hline & & LX-GSA & 0.005872 & 0.006013 & 0.500762 & 0.00293 & 0.011902 & 0.002062 \\
\hline & & PM-GSA & 0.014988 & 0.014736 & 0.572144 & 0.008304 & 0.024337 & 0.003888 \\
\hline & & LX-PM-GSA & 0.005549 & 0.005666 & 0.49244 & 0.002206 & 0.007877 & $\mathbf{0 . 0 0 1 8 3 4}$ \\
\hline
\end{tabular}


On observing the results presented in Table 1 , it is observed that out of the 7 problems considered in this category LX-PM-GSA performed the best in 4 problems, whereas LX-GSA performed best in 2 problems. Also, all algorithms are able to solve one problem, namely $\mathrm{F}_{6}$. It may be thus be concluded that the performance of LXPM-GSA is the best for high dimensional unimodal functions.

On observing the results of Table 2 , it is observed that out of the 6 problems considered in this category LX-PMGSA performed the best in 5 problems, whereas PMGSA performed best in 1 problems. It may be thus be concluded that the performance of LX-PM-GSA is the best for high dimensional multimodal functions.

On observing the results of Table 3 , it is observed that out of the 10 problems considered in this category LXPM-GSA performed the best in 4 problems and LX-GSA performed best in one problem and the performance of
LX-GSA and LX-PM-GSA is same on one problem, namely $F_{19}$, whereas all algorithms are able to solve 4 problems, namely $\mathrm{F}_{16}, \mathrm{~F}_{17}, \mathrm{~F}_{18}$ and $\mathrm{F}_{23}$. It may be thus be concluded that the performance of LX-PM-GSA is the best for low dimensional multimodal functions with fixed dimensions.

In order to observe the behaviour of the objective function value with a passage of iterations the convergence plots of the $F_{3}, F_{4}, F_{5}, F_{6}, F_{7}, F_{8}, F_{9}, F_{11}, F_{12}$, $F_{13}, F_{14}, F_{15}, F_{16}, F_{17}, F_{18}, F_{19}, F_{20}, F_{21}, F_{22}$, and $F_{23}$ functions are shown in Fig. 5-6. On the horizontal axis the iterations are shown whereas on the vertical axis the average best-so-far is shown. Average best-so-far is the average value of objective function in each iteration over 30 runs. From the plots it is concluded that LX-PM-GSA is converging fast towards optima in comparison to other algorithms. The plots of the remaining functions is not shown due to scaling issues.

Table 2. Objective Function Values for High Dimensional Multimodal Functions

\begin{tabular}{|c|c|c|c|c|c|c|c|c|}
\hline Pro. & Dim. & Algorithm & $\begin{array}{l}\text { Average best } \\
\text { so far }\end{array}$ & $\begin{array}{c}\text { Median best } \\
\text { so far }\end{array}$ & $\begin{array}{c}\text { Average } \\
\text { mean fitness }\end{array}$ & Best & Worse & STD \\
\hline \multirow[t]{4}{*}{$\mathrm{F}_{8}$} & 30 & GSA & -2626.2 & -2624.98 & -1072.92 & -3373.13 & -2132.9 & 346.3529 \\
\hline & & LX-GSA & -6284 & -6191.93 & -6284 & -7673.59 & -4849.59 & 676.326 \\
\hline & & PM-GSA & -5149.57 & -5045.6 & -1100.67 & -6070.94 & -4234.38 & 491.3833 \\
\hline & & LX-PM-GSA & -8360.99 & -8216.68 & -8343.59 & -9983.04 & -6785.44 & 805.5085 \\
\hline \multirow[t]{4}{*}{$\mathrm{F}_{9}$} & 30 & GSA & 15.65402 & 13.92943 & 15.65402 & 8.954632 & 28.85379 & 4.494877 \\
\hline & & LX-GSA & 18.87105 & 16.9143 & 18.87105 & 9.949591 & 31.83867 & 4.670301 \\
\hline & & PM-GSA & 13.86309 & 13.92942 & 13.86309 & 8.954632 & 21.88909 & 3.294037 \\
\hline & & LX-PM-GSA & 20.36349 & 18.90422 & 20.36349 & 9.949591 & 43.77816 & 7.347434 \\
\hline \multirow[t]{4}{*}{$\mathrm{F}_{10}$} & 30 & GSA & $1.37 \mathrm{E}-09$ & $1.36 \mathrm{E}-09$ & $2.38 \mathrm{E}-09$ & $1.03 \mathrm{E}-09$ & $1.98 \mathrm{E}-09$ & $2.09 \mathrm{E}-10$ \\
\hline & & LX-GSA & 1.14E-09 & $1.14 \mathrm{E}-09$ & 2.24E-09 & $8.14 \mathrm{E}-10$ & $1.55 \mathrm{E}-09$ & $1.64 \mathrm{E}-10$ \\
\hline & & PM-GSA & $1.4 \mathrm{E}-09$ & $1.4 \mathrm{E}-09$ & $2.39 \mathrm{E}-09$ & $1.09 \mathrm{E}-09$ & $1.92 \mathrm{E}-09$ & $1.94 \mathrm{E}-10$ \\
\hline & & LX-PM-GSA & 1.13E-09 & 1.13E-09 & $2.26 \mathrm{E}-09$ & $7.47 \mathrm{E}-10$ & 1.41E-09 & $1.44 \mathrm{E}-10$ \\
\hline \multirow[t]{4}{*}{$\mathrm{F}_{11}$} & 30 & GSA & 0.001805 & 0 & 0.001805 & 0 & 0.027061 & 0.005955 \\
\hline & & LX-GSA & 0.007624 & 0 & 0.007624 & 0 & 0.041665 & 0.011918 \\
\hline & & PM-GSA & 0.007687 & 0 & 0.007687 & 0 & 0.068846 & 0.018361 \\
\hline & & LX-PM-GSA & 0.001298 & 0 & 0.001298 & 0 & 0.012316 & 0.003279 \\
\hline \multirow[t]{4}{*}{$\mathrm{F}_{12}$} & 30 & GSA & 0.002616 & $2 \mathrm{E}-20$ & 0.003456 & $8.14 \mathrm{E}-21$ & 0.078488 & 0.01433 \\
\hline & & LX-GSA & $1.29 \mathrm{E}-20$ & $1.2 \mathrm{E}-20$ & $5.76 \mathrm{E}-20$ & $7.95 \mathrm{E}-21$ & $2.32 \mathrm{E}-20$ & $3.69 \mathrm{E}-21$ \\
\hline & & PM-GSA & 0.010367 & $2.24 \mathrm{E}-20$ & 0.010367 & $1.27 \mathrm{E}-20$ & 0.103669 & 0.031632 \\
\hline & & LX-PM-GSA & $1.21 \mathrm{E}-20$ & 1.19E-20 & $5.76 \mathrm{E}-20$ & 6.8E-21 & 2.04E-20 & 3.08E-21 \\
\hline \multirow[t]{4}{*}{$\mathrm{F}_{13}$} & 30 & GSA & 3.39E-19 & $3.1 \mathrm{E}-19$ & $1.06 \mathrm{E}-18$ & $1.42 \mathrm{E}-19$ & $5.75 \mathrm{E}-19$ & $1.07 \mathrm{E}-19$ \\
\hline & & LX-GSA & $2.03 \mathrm{E}-19$ & $1.9 \mathrm{E}-19$ & $9.15 \mathrm{E}-19$ & $9.45 \mathrm{E}-20$ & 3.43E-19 & $6.29 \mathrm{E}-20$ \\
\hline & & PM-GSA & $3.42 \mathrm{E}-19$ & $3.48 \mathrm{E}-19$ & $1.03 \mathrm{E}-18$ & $1.33 \mathrm{E}-19$ & $6.04 \mathrm{E}-19$ & $1.19 \mathrm{E}-19$ \\
\hline & & LX-PM-GSA & $1.86 \mathrm{E}-19$ & $1.75 E-19$ & 8.72E-19 & 9E-20 & $3.76 \mathrm{E}-19$ & $6.17 E-20$ \\
\hline
\end{tabular}

Statistically the comparison of the proposed versions with respect to the original GSA is performed using t-test. A pairwise one tailed t-test is applied with $29^{\circ}$ of freedom at 0.05 level of significance over the objective function value of all the problems considered. The null hypothesis is assumed that "there is no difference between algorithms" and alternative hypothesis is "there is difference". The pairwise mean, standard deviation, standard error mean, $\mathrm{p}$-value along with conclusion of the test are listed in Table 4 . A+ shows that version 2 is significantly better than version 1 , A shows the version 2 is alike version $1, \mathrm{~A}$ - shows that version 2 is marginally better than version $1, \mathrm{~B}+$ shows that version 2 is significantly worse than version 1 and B- shows that version 2 is marginally worst than version 1 . The best values are highlighted in bold in Table 4.

On observing the results shown in Table 4 , it can be concluded that if GSA vs LX-GSA is considered then 10 out of the 13 problems show that LX-GSA is significantly better than GSA. If GSA vs PM-GSA is considered then 
7 out of the 13 problems show that PM-GSA is significantly better than GSA. If GSA vs LX-PM-GSA is considered then 10 out of the 13 problems show that LXPM-GSA is significantly better than GSA.

Table 3. Objective Function Values for Low Dimensional Multimodal Functions

\begin{tabular}{|c|c|c|c|c|c|c|c|c|}
\hline Pro. & Dim. & Algorithm & $\begin{array}{l}\text { Average } \\
\text { best so far }\end{array}$ & $\begin{array}{l}\text { Median } \\
\text { best so far }\end{array}$ & $\begin{array}{l}\text { Average mean } \\
\text { fitness }\end{array}$ & Best & Worse & STD \\
\hline \multirow[t]{4}{*}{$\mathrm{F}_{14}$} & 2 & GSA & 2.276057 & 2.001888 & 11.14483 & 0.998004 & 5.968449 & 1.19968 \\
\hline & & LX-GSA & 1.263078 & 0.998004 & 1.263078 & 0.998004 & 1.992031 & 0.44709 \\
\hline & & PM-GSA & 0.998004 & 0.998004 & 11.97185 & 0.998004 & 0.998004 & $1.14 \mathrm{E}-09$ \\
\hline & & LX-PM-GSA & 0.998004 & 0.998004 & 0.998004 & 0.998004 & 0.998004 & $\mathbf{0}$ \\
\hline \multirow[t]{4}{*}{$\mathrm{F}_{15}$} & 4 & GSA & 0.003154 & 0.00216 & 0.759498 & 0.001598 & 0.008348 & 0.001833 \\
\hline & & LX-GSA & 0.000951 & 0.000781 & 0.001147 & 0.000488 & 0.001869 & 0.000347 \\
\hline & & PM-GSA & 0.001448 & 0.001603 & 0.745155 & 0.000542 & 0.002252 & 0.000533 \\
\hline & & LX-PM-GSA & 0.001 & 0.001003 & 0.001065 & 0.000663 & 0.001236 & 0.000216 \\
\hline \multirow[t]{4}{*}{$\mathrm{F}_{16}$} & 2 & GSA & -1.03163 & -1.03163 & -1.03163 & -1.03163 & -1.03163 & $6.18 \mathrm{E}-16$ \\
\hline & & LX-GSA & -1.03163 & -1.03163 & -1.03163 & -1.03163 & -1.03163 & $6.25 \mathrm{E}-16$ \\
\hline & & PM-GSA & -1.03163 & -1.03163 & -1.03163 & -1.03163 & -1.03163 & $6.39 \mathrm{E}-16$ \\
\hline & & LX-PM-GSA & -1.03163 & -1.03163 & -1.03163 & -1.03163 & -1.03163 & $6.45 \mathrm{E}-16$ \\
\hline \multirow[t]{4}{*}{$\mathrm{F}_{17}$} & 2 & GSA & 0.397887 & 0.397887 & 0.397887 & 0.397887 & 0.397887 & 0 \\
\hline & & LX-GSA & 0.397887 & 0.397887 & 0.397887 & 0.397887 & 0.397887 & 0 \\
\hline & & PM-GSA & 0.397887 & 0.397887 & 0.397887 & 0.397887 & 0.397887 & 0 \\
\hline & & LX-PM-GSA & 0.397887 & 0.397887 & 0.397887 & 0.397887 & 0.397887 & 0 \\
\hline \multirow[t]{4}{*}{$\mathrm{F}_{18}$} & 2 & GSA & 3 & 3 & 3 & 3 & 3 & $1.78 \mathrm{E}-15$ \\
\hline & & LX-GSA & 3 & 3 & 3 & 3 & 3 & $1.71 \mathrm{E}-15$ \\
\hline & & PM-GSA & 3 & 3 & 3 & 3 & 3 & $1.61 \mathrm{E}-15$ \\
\hline & & LX-PM-GSA & 3 & 3 & 3 & 3 & 3 & $2.91 \mathrm{E}-15$ \\
\hline \multirow[t]{4}{*}{$\mathrm{F}_{19}$} & 3 & GSA & -3.85648 & -3.8549 & -3.85648 & -3.86278 & -3.8549 & 0.003205 \\
\hline & & LX-GSA & -3.86278 & -3.86278 & -3.86278 & -3.86278 & -3.86278 & 3.16E-15 \\
\hline & & PM-GSA & -3.86075 & -3.86269 & -3.85648 & -3.86278 & -3.8549 & 0.003324 \\
\hline & & LX-PM-GSA & -3.86278 & -3.86278 & -3.86278 & -3.86278 & -3.86278 & 3.16E-15 \\
\hline \multirow[t]{4}{*}{$\mathrm{F}_{20}$} & 6 & GSA & -2.06163 & -2.02263 & -1.29549 & -3.0769 & -0.83909 & 0.602156 \\
\hline & & LX-GSA & -3.27449 & $-\mathbf{3 . 3 2 2 3 7}$ & -3.27449 & $-\mathbf{3 . 3 2 2 3 7}$ & -3.1974 & 0.059645 \\
\hline & & PM-GSA & -3.12652 & -3.13681 & -1.24446 & -3.32237 & -2.80401 & 0.159813 \\
\hline & & LX-PM-GSA & -3.28641 & $-\mathbf{3 . 3 2 2 3 7}$ & -3.28641 & -3.32237 & -3.1974 & 0.055868 \\
\hline \multirow[t]{4}{*}{$\mathrm{F}_{21}$} & 4 & GSA & -4.91606 & -5.0552 & -4.91606 & -5.0552 & -0.88098 & 0.762104 \\
\hline & & LX-GSA & -6.05559 & -5.0552 & -6.05557 & -10.1532 & -5.0552 & 2.037327 \\
\hline & & PM-GSA & -6.63124 & -5.0552 & -5.08599 & -10.1532 & -2.64875 & 2.479425 \\
\hline & & LX-PM-GSA & -6.92447 & -5.0552 & -6.92447 & -10.1532 & -5.0552 & 2.498697 \\
\hline \multirow[t]{4}{*}{$\mathrm{F}_{22}$} & 4 & GSA & -6.68225 & -5.08767 & -6.68225 & -10.4029 & -5.08767 & 2.477402 \\
\hline & & LX-GSA & -9.16271 & -10.4029 & -9.16271 & -10.4029 & -5.08767 & 2.286539 \\
\hline & & PM-GSA & -8.09966 & -10.4029 & -8.09966 & -10.4029 & -5.08767 & 2.678932 \\
\hline & & LX-PM-GSA & -9.51706 & -10.4029 & -9.51706 & -10.4029 & -5.08767 & 2.014747 \\
\hline \multirow[t]{4}{*}{$\mathrm{F}_{23}$} & 4 & GSA & -10.5364 & -10.5364 & -10.5364 & -10.5364 & -10.5364 & $1.55 \mathrm{E}-15$ \\
\hline & & LX-GSA & -10.5364 & -10.5364 & -10.5364 & -10.5364 & -10.5364 & $1.58 \mathrm{E}-15$ \\
\hline & & PM-GSA & -10.5364 & -10.5364 & -10.5364 & -10.5364 & -10.5364 & $1.75 \mathrm{E}-15$ \\
\hline & & LX-PM-GSA & -10.5364 & -10.5364 & -10.5364 & -10.5364 & -10.5364 & $1.62 \mathrm{E}-15$ \\
\hline
\end{tabular}


F3

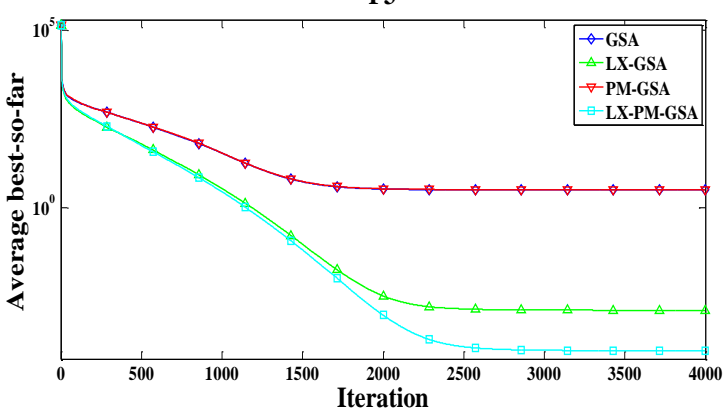

F5

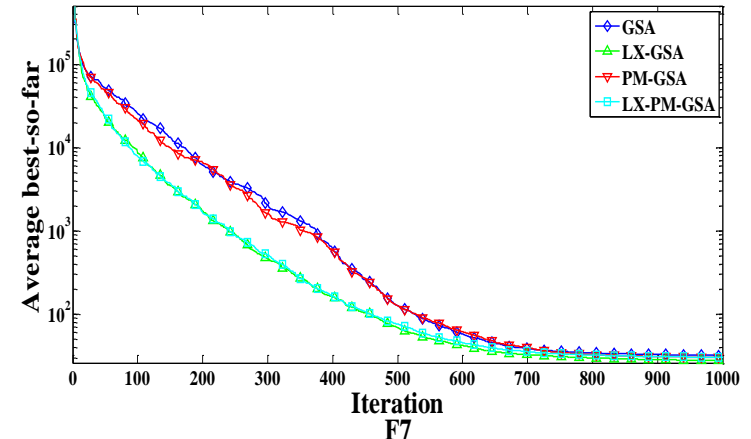

F7

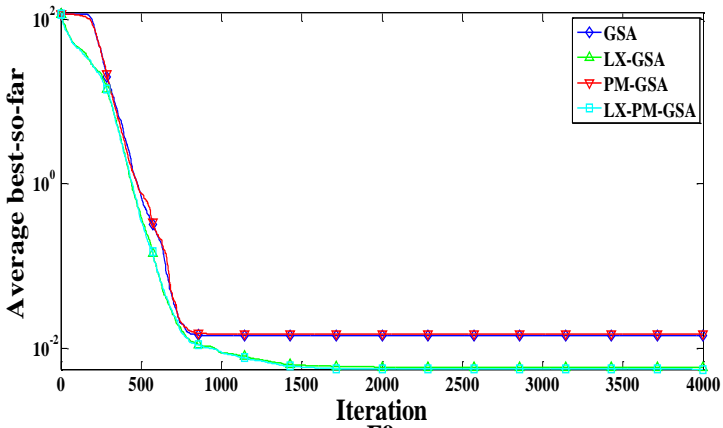

F9

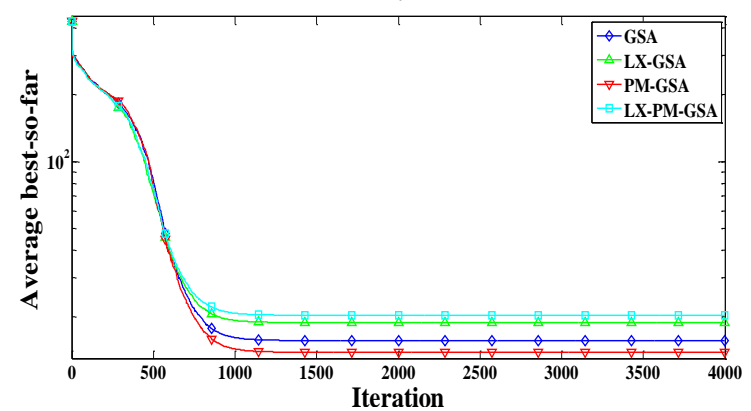

F12

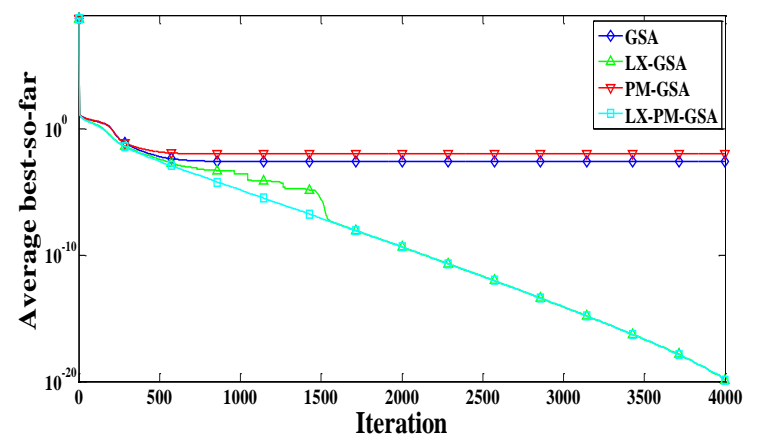

F4



F6

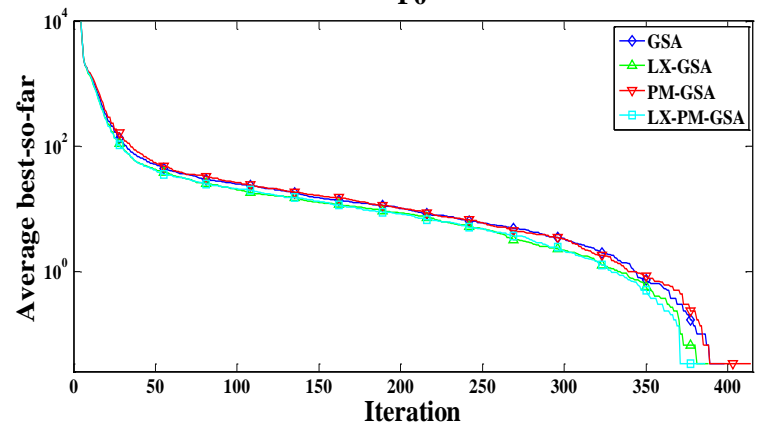

F8

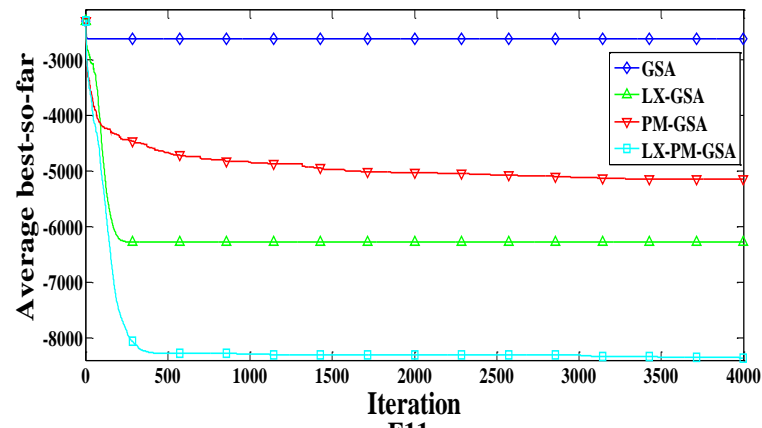

F11

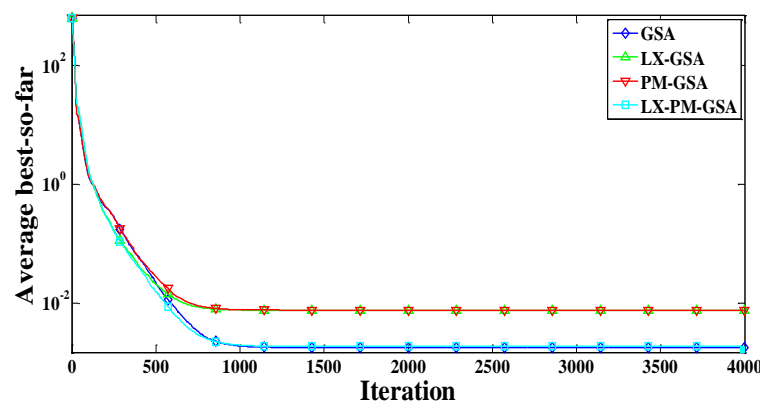

F13

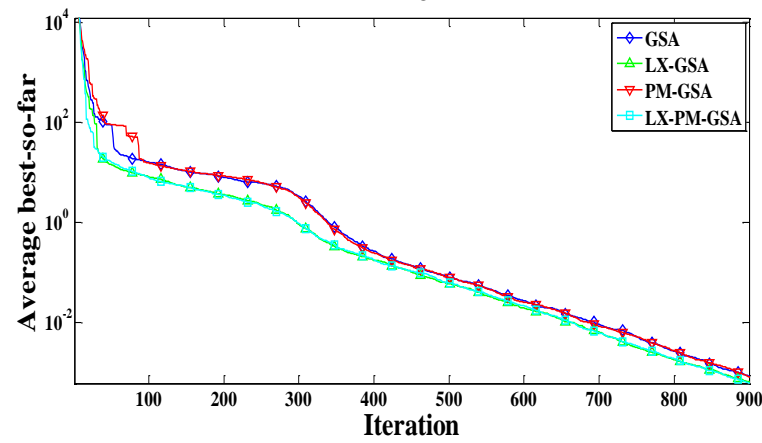

Fig.5. Iteration wise convergence Plot of Average Best-So-Far for Functions $F_{3}$ to $F_{9}$ and $F_{11}$ to $F_{13}$ 

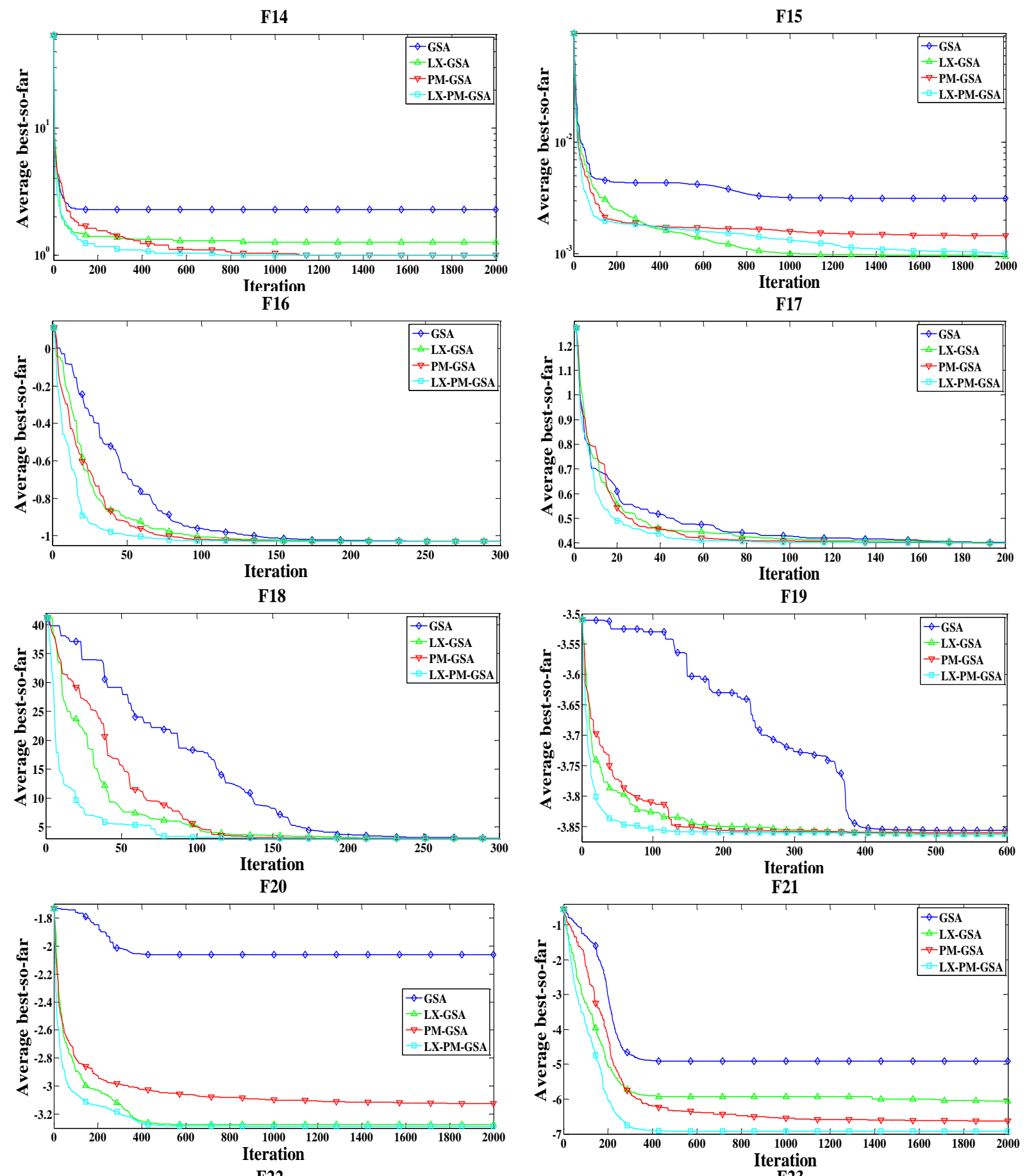

F22
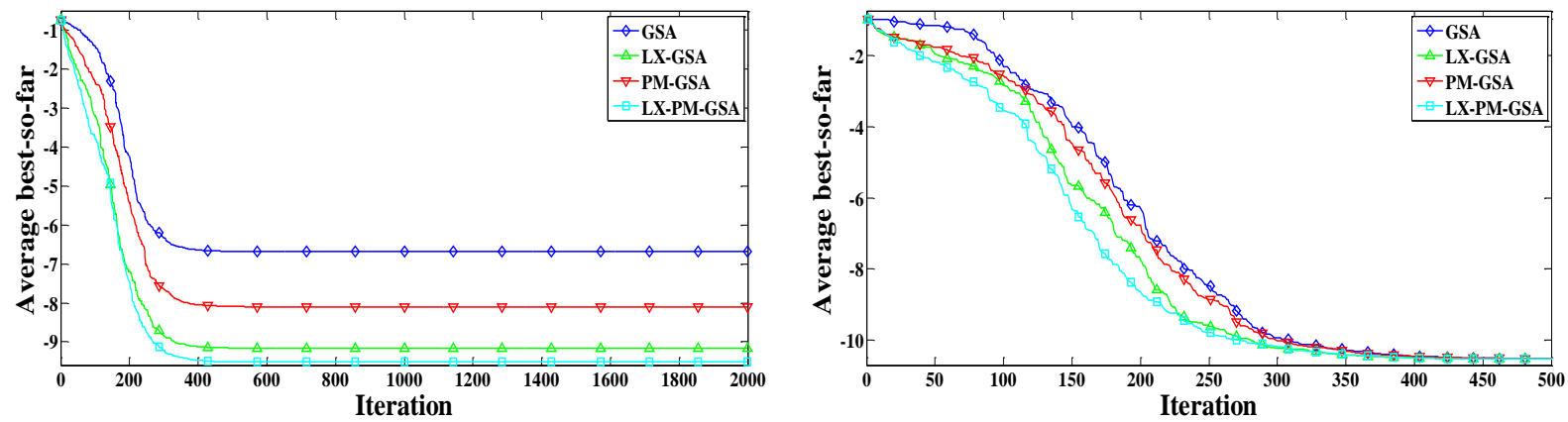

Fig.6. Iteration wise Convergence Plot of Average Best-So-Far for Functions $\mathrm{F}_{14}$ to $\mathrm{F}_{23}$. 
Table 4. Pairwise T-Test Results of Objective Function Values With 95\% Confidence Interval at 0.05 Level of Significance

\begin{tabular}{|c|c|c|c|c|c|c|}
\hline Version 1 vs Version 2 & Pro. & Mean & $\begin{array}{c}\text { Standard } \\
\text { Deviation }\end{array}$ & $\begin{array}{c}\text { Standard } \\
\text { error mean }\end{array}$ & p-value & Conclusion \\
\hline \multirow[t]{13}{*}{ GSA vs LX-GSA } & $\mathrm{F}_{3}$ & 3.21634 & 3.26429 & 0.59598 & 0 & $\mathrm{~A}+$ \\
\hline & $\mathrm{F}_{5}$ & 1.20263 & 0.30630 & 0.05592 & 0 & $\mathrm{~A}+$ \\
\hline & $\mathrm{F}_{7}$ & 0.00847 & 0.00362 & 0.00066 & 0 & $\mathrm{~A}+$ \\
\hline & $\mathrm{F}_{8}$ & 3657.80391 & 659.10395 & 120.33537 & 0 & $\mathrm{~A}+$ \\
\hline & $\mathrm{F}_{9}$ & -3.21703 & 5.89311 & 1.07593 & 0.003 & $\mathrm{~B}+$ \\
\hline & $\mathrm{F}_{11}$ & -0.00582 & 0.01404 & 0.00256 & 0.0155 & $\mathrm{~B}+$ \\
\hline & $\mathrm{F}_{12}$ & 0.00262 & 0.01433 & 0.00262 & 0.163 & A- \\
\hline & $\mathrm{F}_{14}$ & 1.01298 & 1.16672 & 0.21301 & 0 & $\mathrm{~A}+$ \\
\hline & $\mathrm{F}_{15}$ & 0.00220 & 0.00170 & 0.00031 & 0 & $\mathrm{~A}+$ \\
\hline & $\mathrm{F}_{19}$ & 0.00630 & 0.00321 & 0.00059 & 0 & $\mathrm{~A}+$ \\
\hline & $\mathrm{F}_{20}$ & 1.21286 & 0.60346 & 0.11018 & 0 & $\mathrm{~A}+$ \\
\hline & $\mathrm{F}_{21}$ & 1.13953 & 2.10796 & 0.38486 & 0.003 & $\mathrm{~A}+$ \\
\hline & $\mathrm{F}_{22}$ & 2.48046 & 3.34230 & 0.61022 & 0 & $\mathrm{~A}+$ \\
\hline \multirow{13}{*}{ GSA vs PM-GSA } & $\mathrm{F}_{3}$ & -0.03730 & 2.61039 & 0.47659 & 0.469 & B- \\
\hline & $\mathrm{F}_{5}$ & -1.84778 & 10.45474 & 1.90877 & 0.1705 & B- \\
\hline & $\mathrm{F}_{7}$ & -0.00065 & 0.00602 & 0.00110 & 0.2795 & B- \\
\hline & $\mathrm{F}_{8}$ & 2523.37149 & 649.08325 & 118.50585 & 0 & $\mathrm{~A}+$ \\
\hline & $\mathrm{F}_{9}$ & 1.79092 & 6.34346 & 1.15815 & 0.0665 & A- \\
\hline & $\mathrm{F}_{11}$ & -0.00588 & 0.01787 & 0.00326 & 0.041 & $\mathrm{~B}+$ \\
\hline & $F_{12}$ & -0.00775 & 0.03553 & 0.00649 & 0.121 & B- \\
\hline & $\mathrm{F}_{14}$ & 1.27805 & 1.19968 & 0.21903 & 0 & $\mathrm{~A}+$ \\
\hline & $\mathrm{F}_{15}$ & 0.00171 & 0.00194 & 0.00035 & 0 & $\mathrm{~A}+$ \\
\hline & $\mathrm{F}_{19}$ & 0.00427 & 0.00483 & 0.00088 & 0 & $\mathrm{~A}+$ \\
\hline & $\mathrm{F}_{20}$ & 1.06489 & 0.60345 & 0.11017 & 0 & $\mathrm{~A}+$ \\
\hline & $\mathrm{F}_{21}$ & 1.71518 & 2.77532 & 0.50670 & 0.001 & $\mathrm{~A}+$ \\
\hline & $\mathrm{F}_{22}$ & 1.41740 & 3.10036 & 0.56604 & 0.009 & $\mathrm{~A}+$ \\
\hline \multirow[t]{13}{*}{ GSA vs LX-PM-GSA } & $\mathrm{F}_{3}$ & 3.21753 & 3.26398 & 0.59592 & 0 & $\mathrm{~A}+$ \\
\hline & $\mathrm{F}_{5}$ & 0.97208 & 1.12065 & 0.20460 & 0 & $\mathrm{~A}+$ \\
\hline & $\mathrm{F}_{7}$ & 0.00879 & 0.00475 & 0.00087 & 0 & $\mathrm{~A}+$ \\
\hline & $\mathrm{F}_{8}$ & 5734.79118 & 959.53312 & 175.18598 & 0 & $\mathrm{~A}+$ \\
\hline & $\mathrm{F}_{9}$ & -4.70947 & 9.19697 & 1.67913 & 0.0045 & $\mathrm{~B}+$ \\
\hline & $\mathrm{F}_{11}$ & 0.00051 & 0.00650 & 0.00119 & 0.3365 & A- \\
\hline & $\mathrm{F}_{12}$ & 0.00262 & 0.01433 & 0.00262 & 0.163 & A- \\
\hline & $\mathrm{F}_{14}$ & 1.27805 & 1.19968 & 0.21903 & 0 & $\mathrm{~A}+$ \\
\hline & $\mathrm{F}_{15}$ & 0.00215 & 0.00194 & 0.00035 & 0 & $\mathrm{~A}+$ \\
\hline & $\mathrm{F}_{19}$ & 0.00630 & 0.00321 & 0.00059 & 0 & $\mathrm{~A}+$ \\
\hline & $\mathrm{F}_{20}$ & 1.22478 & 0.59786 & 0.10915 & 0 & $\mathrm{~A}+$ \\
\hline & $\mathrm{F}_{21}$ & 2.00841 & 2.50722 & 0.45775 & 0 & $\mathrm{~A}+$ \\
\hline & $\mathrm{F}_{22}$ & 2.83481 & 3.03686 & 0.55445 & 0 & $\mathrm{~A}+$ \\
\hline
\end{tabular}


Table 5. Success rate, Average Function Evaluation of Successful Run and Average Execution Time of Successful Run of GSA, LX-GSA, PM-GSA and LX-PM-GSA

\begin{tabular}{|c|c|c|c|c|c|c|c|c|c|c|c|c|}
\hline \multirow[b]{2}{*}{$\begin{array}{c}\text { Proble } \\
\text { m }\end{array}$} & \multicolumn{4}{|c|}{ Success rate } & \multicolumn{4}{|c|}{$\begin{array}{c}\text { Average function evaluation of successful } \\
\text { run }\end{array}$} & \multicolumn{4}{|c|}{ Average execution time of successful run } \\
\hline & GSA & $\begin{array}{l}\text { LX- } \\
\text { GSA }\end{array}$ & $\begin{array}{l}\text { PM- } \\
\text { GSA }\end{array}$ & $\begin{array}{l}\text { LX- } \\
\text { PM- } \\
\text { GSA }\end{array}$ & GSA & $\begin{array}{l}\text { LX- } \\
\text { GSA }\end{array}$ & $\begin{array}{l}\text { PM- } \\
\text { GSA }\end{array}$ & $\begin{array}{l}\text { LX-PM- } \\
\text { GSA }\end{array}$ & GSA & $\begin{array}{l}\text { LX- } \\
\text { GSA }\end{array}$ & $\begin{array}{l}\text { PM- } \\
\text { GSA }\end{array}$ & $\begin{array}{l}\text { LX-PM- } \\
\text { GSA }\end{array}$ \\
\hline $\mathrm{F} 1$ & 100 & 100 & 100 & 100 & 43173 & 44262 & 44128 & 45105 & 8.47 & 8.99 & 8.80 & 9.02 \\
\hline $\mathrm{F} 2$ & 100 & 100 & 100 & 100 & 79907 & 82585 & 81601 & 84113 & 13.90 & 16.31 & 15.40 & 17.58 \\
\hline F3 & 0 & 100 & 0 & 100 & - & 88899 & - & 78421 & - & 26.34 & - & 24.35 \\
\hline $\mathrm{F} 4$ & 100 & 100 & 100 & 100 & 57397 & 58840 & 58640 & 60117 & 10.38 & 11.64 & 11.09 & 12.26 \\
\hline F5 & 0 & 0 & 0 & 0 & - & - & - & - & - & - & - & - \\
\hline F6 & 100 & 100 & 100 & 100 & 18009 & 17882 & 18625 & 18369 & 3.46 & 3.57 & 3.60 & 3.66 \\
\hline F7 & 22 & 96 & 16 & 100 & 39104 & 49547 & 40250 & 49705 & 8.21 & 12.27 & 9.28 & 12.64 \\
\hline F8 & 0 & 0 & 0 & 0 & - & - & - & - & - & - & - & - \\
\hline F9 & 0 & 0 & 0 & 0 & - & - & - & - & - & - & - & - \\
\hline F10 & 100 & 100 & 100 & 100 & 62910 & 65031 & 64345 & 66258 & 11.51 & 13.28 & 12.58 & 14.03 \\
\hline F11 & 80 & 74 & 80 & 80 & 30023 & 28620 & 30734 & 31799 & 6.06 & 6.46 & 6.47 & 7.31 \\
\hline F12 & 94 & 100 & 96 & 100 & 21129 & 20203 & 21677 & 20408 & 5.01 & 4.96 & 5.26 & 5.02 \\
\hline F13 & 98 & 100 & 100 & 100 & 34539 & 34867 & 35455 & 35129 & 7.94 & 8.25 & 8.36 & 8.54 \\
\hline F14 & 8 & 86 & 18 & 100 & 2812 & 14739 & 1976 & 5424 & 0.75 & 4.19 & 0.55 & 1.58 \\
\hline F15 & 100 & 100 & 98 & 100 & 1452 & 1783 & 1743 & 1856 & 0.25 & 0.29 & 0.30 & 0.32 \\
\hline F16 & 100 & 100 & 100 & 100 & 7874 & 7857 & 7297 & 8257 & 1.22 & 1.18 & 1.09 & 1.26 \\
\hline F17 & 100 & 100 & 100 & 100 & 6800 & 7357 & 7708 & 7767 & 1.05 & 1.12 & 1.19 & 1.21 \\
\hline F18 & 100 & 100 & 100 & 100 & 18675 & 19154 & 19222 & 19455 & 2.75 & 2.91 & 2.87 & 3.06 \\
\hline F19 & 100 & 100 & 100 & 100 & 19433 & 18703 & 19769 & 19539 & 3.19 & 3.16 & 3.22 & 3.30 \\
\hline $\mathrm{F} 20$ & 0 & 72 & 2 & 68 & - & 24634 & 23204 & 25368 & - & 4.689 & 4.36 & 5.0869 \\
\hline $\mathrm{F} 21$ & 0 & 24 & 0 & 30 & - & 25807 & - & 26157 & - & 5.31 & - & 5.55 \\
\hline $\mathrm{F} 22$ & 44 & 72 & 52 & 82 & 24811 & 25833.3 & 25808 & 26745 & 4.22 & 4.92 & 4.75 & 5.16 \\
\hline $\mathrm{F} 23$ & 100 & 100 & 100 & 100 & 24897 & 25742 & 25392 & 26650 & 5.67 & 6.02 & 5.83 & 6.22 \\
\hline
\end{tabular}

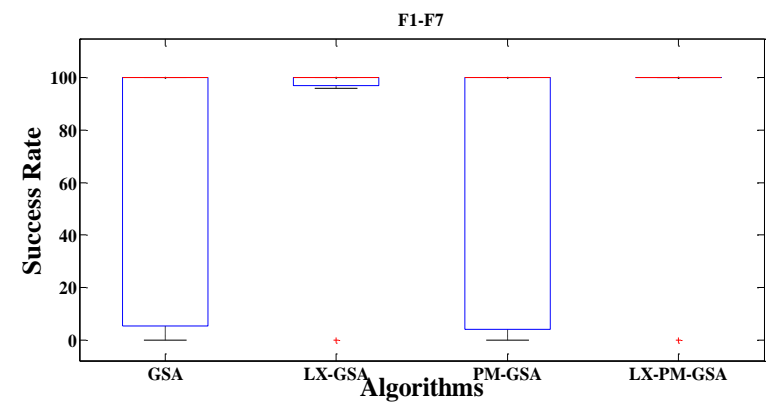

(a)

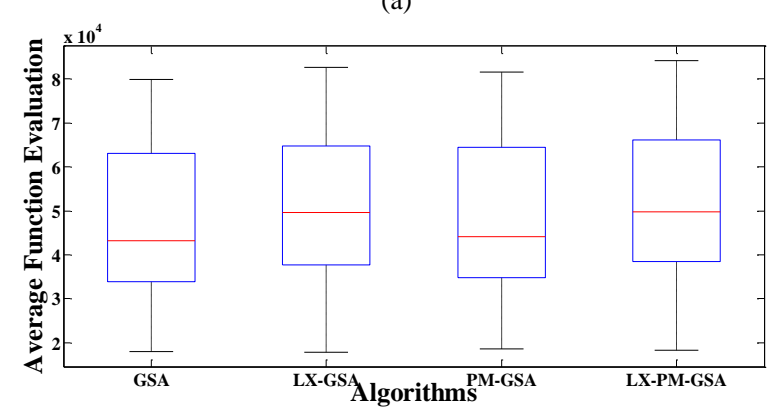

(b)

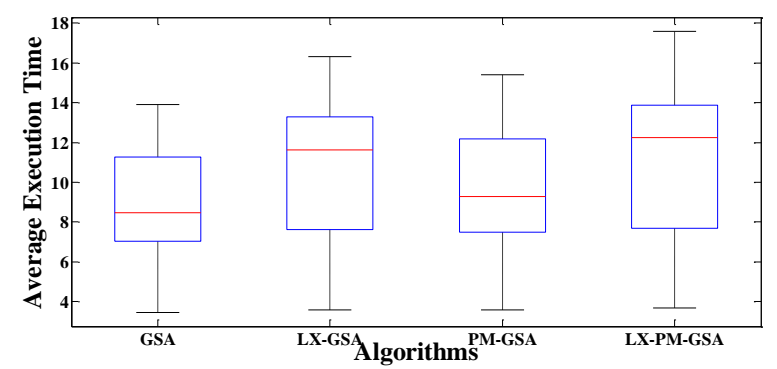

(c)

Fig.7. Boxplot Corresponding to (a) Success Rate, (b) Average Function Evaluations, (c) Average Execution Time of Functions $F_{1}-F_{7}$

The $p$-value of $F_{1}, F_{2}, F_{4}, F_{6}, F_{10}, F_{13}, F_{16}, F_{17}$ and $F_{18}$ could not be evaluated because the standard error of the difference is 0 . Hence on the basis of t-tests it can be concluded that LX-PM-GSA is definitely a winner over GSA, LX-GSA and PM-GSA.

\section{B. Analysis of Results based on Experiment II}

In order to observe the reliability, computational cost and convergence rate of the algorithms considered, 
Success Rate (SR), Average Function Evaluation (AFE) and Average Execution Time (AET) of all algorithms are recorded in Table 5. The best values are highlighted in bold in Table 5 .

From this table it is observed that out of 4 algorithms, there is no algorithm which can solve all 23 problems with $100 \%$ success. GSA and PM-GSA solve 11 problems with $100 \%$ success, LX-GSA solve 14 problems with $100 \%$ success and LX-PM-GSA solve 16 problems with $100 \%$ success. None of them could solve 3 problems with $100 \%$ success. Another observation is that the majority of the problems have been solve by LXPM-GSA but in most of the problems, GSA takes less average function evaluation and average execution time. The boxplot of success rate, average function evaluation of successful run and average execution time of successful run of each algorithm is plotted in Fig.7 for high dimensional unimodal functions namely $\mathrm{F}_{1}-\mathrm{F}_{7}$, Fig. 8 for high dimensional multimodal functions namely $\mathrm{F}_{8^{-}}$ $F_{13}$ and Fig. 9 for low dimensional multimodal functions namely $\mathrm{F}_{14}-\mathrm{F}_{23}$. For the fair comparison, a function is not added in the boxplot of average function evaluation and average execution time if it is not solved by least one algorithm.



(a)

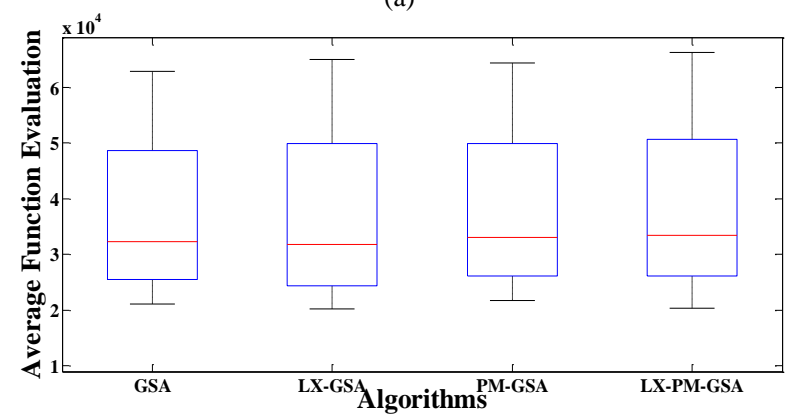

(b)

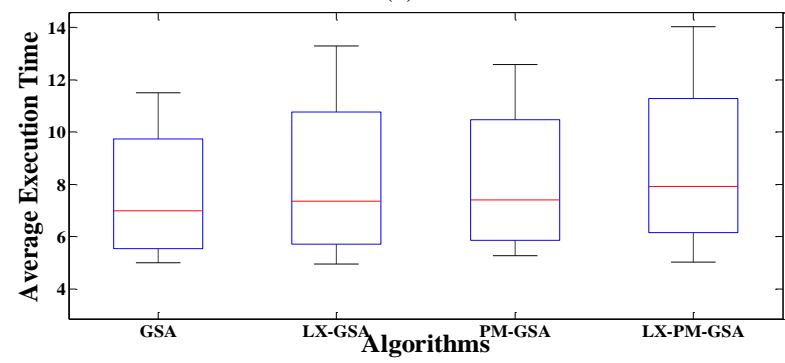

(c)

Fig.8. Boxplot Corresponding to (a) Success Rate, (b) Average Function Evaluations, (c) Average Execution Time Of Functions $\mathrm{F}_{8}-\mathrm{F}_{13}$
If all criteria (SR, AFE, AET) are taken together, then it is difficult to say which one is the best among all. In order to analyse the consolidated effect of the SR, AFE and AET, a comparison among them is made on the basis of the Performance Index (PI) plot. The purpose of the analysis is to observe if the proposed strategies show an improvement over the existing ones or not. The design of PI is such that specified weighted importance is given to the success rate, number of function evaluations of successful runs and computational time of successful runs.

The value of Performance Index $\mathrm{PI}_{\mathrm{j}}$ for $\mathrm{jth}$ algorithm is evaluated by:

$$
P I_{j}=\frac{1}{N} \sum_{i=1}^{N}\left(w_{1} \alpha_{1}^{i}+w_{2} \alpha_{2}^{i}+w_{3} \alpha_{3}^{i}\right)
$$

Where

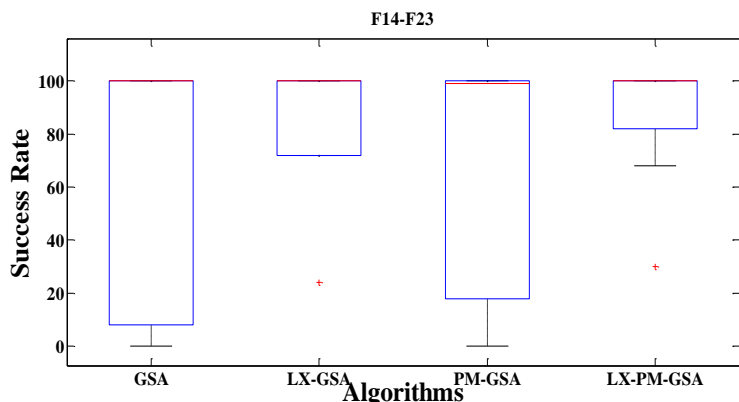

(a)

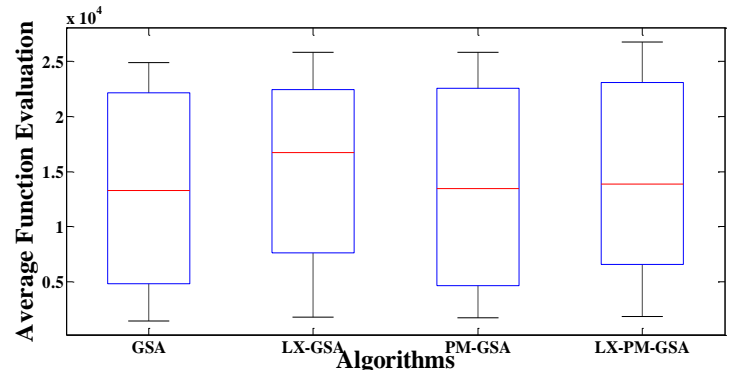

(b)

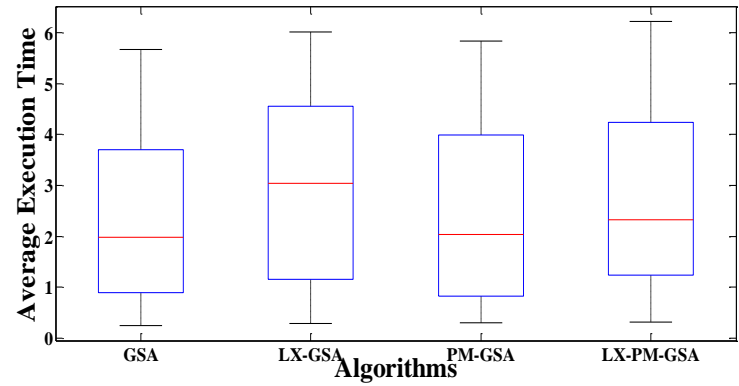

(c)

Fig.9. Boxplot Corresponding to (a) Success Rate, (b) Average Function Evaluations, (c) Average Execution Time of Functions F14-F23

$$
\alpha_{1}^{i}=\frac{S r^{i}}{T r^{i}}
$$

$$
\alpha_{2}^{i}= \begin{cases}\frac{M f^{i}}{A f^{i}} & \text { if } S r^{i}>0 \\ 0 & \text { if } S r^{i}=0\end{cases}
$$




$$
\alpha_{3}^{i}= \begin{cases}\frac{M t^{i}}{A t^{i}} & \text { if } S r^{i}>0 \\ 0 & \text { if } S r^{i}=0\end{cases}
$$

Here, $\mathbf{N}$ is the total number of considered problems and $i=1, \ldots, N \cdot T r^{i}$ represents the total number of times the problem $i$ is solved and $S r^{i}$ is the number of times problem $i$ is solved successfully. $A f^{i}$ is the average number of function evaluations used by algorithm $j$ to obtain the optimal solution of problem $i$ in case of successful runs, and $M f^{i}$ is the minimum of the average number of function evaluation of successful run. Similarly, $A t^{i}$ is average time required by algorithm $j$ to obtain the optimal solution of problem $i$ in case of successful runs, and $M t^{i}$ is minimum of the average time by all the algorithms under comparison to obtain the optimal solution of problem $i$. Further $w_{1}, w_{2}$ and $w_{3}$ are nonnegative assigned weight to the percentage of success, average number of function evaluations used in successful run and the average execution time of successful runs respectively with $w_{1}+w_{2}+w_{3}=1$. Algorithm having largest PI is the winner, amongst the considered algorithms. In order to analyse the relative performance of GSA, LX-GSA, PM-GSA and LX-PMGSA. Equal weights are assigned to two terms $\left(w_{1}, w_{2}\right.$ and $\left.w_{3}\right)$ at a time. Therefore $P I_{j}$ becomes a function of single variable. Following three cases are possible

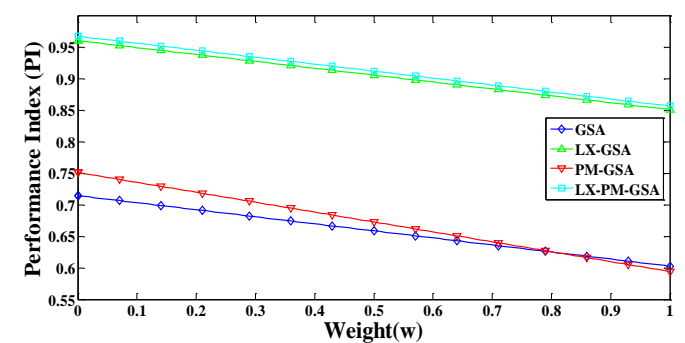

(a)

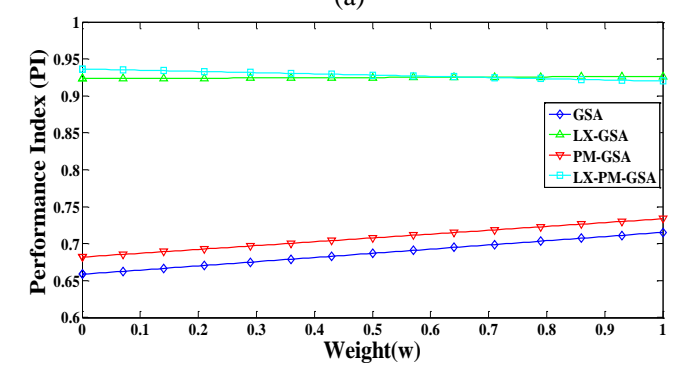

(b)



(c)

Fig.10. Performance Index of GSA, LX-GSA, PM-GSA and LX-PMGSA on $F_{1}-F_{7}$ when (a) $w_{1}$ varies, (b) when $w_{2}$ varies and (c) $w_{3}$ varies.
(i) $w_{1}=w, w_{2}=w_{3}=(1-w) / 2 ; 0 \leq w \leq 1$
(ii) $w_{2}=w, w_{1}=w_{3}=(1-w) / 2 ; 0 \leq w \leq 1$
(ii) $w_{3}=w, w_{1}=w_{2}=(1-w) / 2 ; 0 \leq w \leq 1$

Fig. 10 shows the Performance Index graphs corresponding to each of these three cases on high dimensional unimodal function. Fig. 10(a) corresponds to weight assigned for success rate $w$ is varied. Fig. 10(b) corresponds to weight assign for average function evaluations $w$ is varied and Fig. 10(c) corresponds to weight assigned for average time of the successful runs $w$ is varied. It is clear from the figures, proposed algorithms are significantly better in comparison to GSA and LX-PM-GSA is best among them.

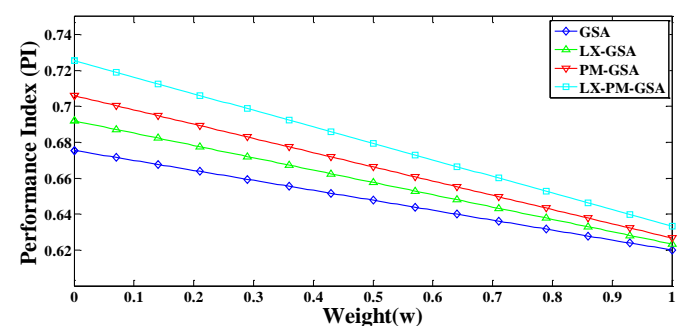

(a)

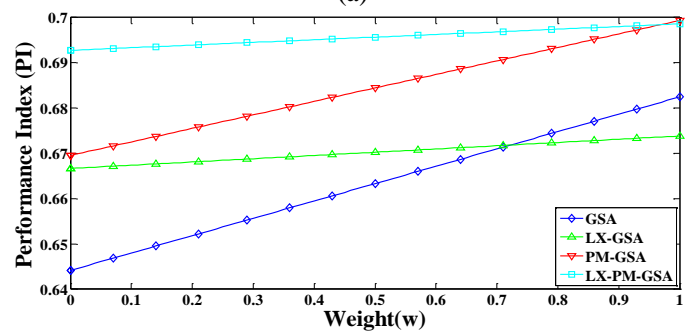

(b)

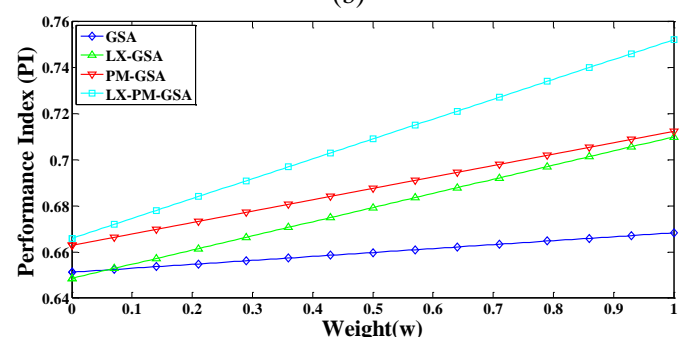

(c)

Fig.11. Performance Index of GSA, LX-GSA, PM-GSA and LX-PMGSA on F8-F13 when (a) w1 varies, (b) when w2 varies and (c) w3 varies.

Similarly, Fig. 11 shows the Performance Index graphs corresponding to each of these three cases on high dimensional multimodal function and Fig. 12 shows the Performance Index graphs corresponding to each of these three cases on low dimensional multimodal function. Fig. 11(a) and 12(a) correspond to weight assigned for success rate $w$ is varied. Fig. 11(b) and 12(b) correspond to weight assign for average function evaluations $w$ is varied and Fig. 11(c) and 12(c) correspond to weight assigned for average time of the successful runs $w$ is varied. It is clear from the figures, proposed algorithms are significantly better in comparison to GSA. LX-PMGSA is best among them on high dimensional 
multimodal function while LX-GSA is little bit less costly as compared to LX-PM-GSA on low dimensional multimodal function.

\section{EXPERIMENT - III: PERFORMANCE ON CEC 2014 BENCHMARKS}

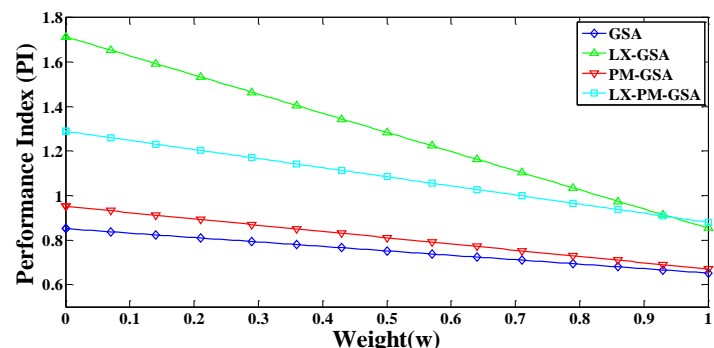

(a)

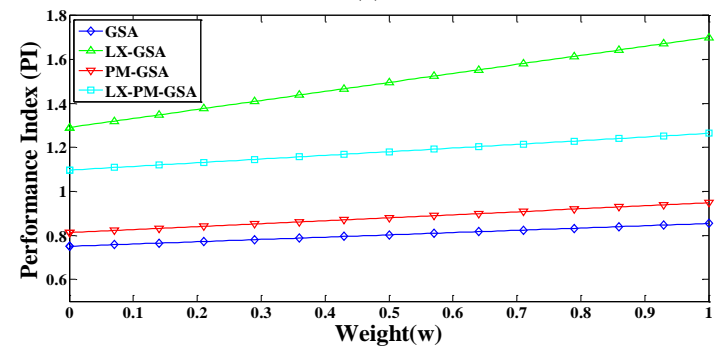

(b)

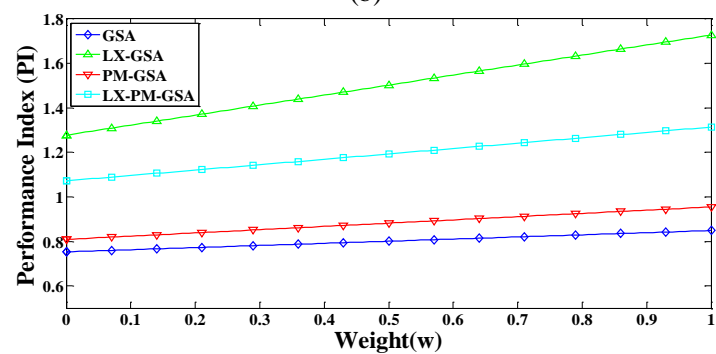

(c)

Fig. 12. Performance Index of GSA, LX-GSA, PM-GSA and LX-PMGSA on $F_{14}-F_{23}$ when (a) $w_{1}$ varies, (b) when $w_{2}$ varies and (c) $w_{3}$ varies.
The performance of the algorithms is also investigated on shifted and rotated problems. Therefore, in experiment III, the CEC 2014 Benchmark is considered, which contains a number of shifted and rotated problems. The details of the problems can be found in Liang et al [38]. The other parameters and criteria are kept as in Liang et al [38]. Problems considered are of dimension 30.

The termination criteria is set as maximum number of function evaluation $=30 \times 10^{4}$ or if error value is smaller than $10^{-8}$. All the considered algorithms are run 51 times. The best, worst, median, mean and standard variance of the objective function error of 51 runs are listed in Table 6. As desired in CEC 2014 criteria, error value smaller than $10^{-8}$ is taken as zero. The best values are highlighted in bold.

From the Table 6, it is observed that out 30 problems, in 11 problems, namely in Problem no. 1, 3, 8, 10, 14, 16, $18,21,22,26,30$, LX-PM-GSA is better than the other three algorithms. In 9 problems, namely Problem no. 6, 7, $11,12,15,19,23,28,29$, GSA is better than LX-GSA, PM-GSA and LX-PM-GSA. There are 2 problems in which performance of PM-GSA is better. In Problems no 2, PM-GSA finds the best solution in comparison to the other algorithms but worst, median, mean, STD are better of LX-GSA. In 4 problems, namely Problem no. 5, 13, 20 , 24, LX-GSA is better than other algorithm. In problem no. 17, LX-GSA find better solution but worst, median, mean, STD are better of LX-PM-GSA. Problem no. 3 is solved by LX-PM-GSA however GSA and LXGSA also find optimal but their success rate is not $100 \%$. Problem no. 4 is solved by all the algorithms. Problem no 7 is solved by GSA and LX-GSA, PM-GSA LX-PM-GSA also find optimal but their success rate is not $100 \%$. In problem no 25 all algorithms find same function error. Overall speaking it can be concluded that the performance of LXPM-GSA is the best in comparison to the remaining three algorithms.

Table 6. Comparison of the objective function values of the 30-dimensional CEC 2014 Benchmark problems

\begin{tabular}{|c|l|c|c|c|c|c|}
\hline Pro. & Algorithm & Best & Worst & Median & Mean & STD \\
\hline 1 & GSA & 44.45694617 & 8797.88912532 & 1933.96707685 & 2690.67684839 & 2110.85690853 \\
\hline & LX-GSA & 0.53772610 & 2193.06456601 & $\mathbf{9 5 . 0 8 3 8 1 2 9 6}$ & $\mathbf{2 6 4 . 4 6 0 9 6 6 1 0}$ & 457.13320027 \\
\hline & PM-GSA & 135.15494725 & 11281.14399315 & 2340.86021306 & 2946.95941802 & 2592.63940594 \\
\hline & LX-PM-GSA & $\mathbf{0 . 0 0 0 3 5 5 0 0}$ & $\mathbf{1 9 8 7 . 5 8 9 7 7 8 0 8}$ & 168.85177483 & 309.29514874 & $\mathbf{4 0 5 . 5 5 9 4 6 6 0 7}$ \\
\hline 2 & GSA & 4.19194950 & 25133.49337662 & 5899.50394061 & 7887.48694152 & 7173.98763828 \\
\hline & LX-GSA & 966.72807201 & $\mathbf{1 2 0 5 5 . 4 4 6 1 0 8 6 6}$ & $\mathbf{3 6 7 0 . 9 1 1 4 5 2 4 3}$ & $\mathbf{3 9 5 4 . 0 6 3 4 4 2 5 5}$ & $\mathbf{2 2 2 9 . 8 8 8 8 0 7 0 4}$ \\
\hline & PM-GSA & $\mathbf{2 . 0 1 8 5 2 4 0 9}$ & 24496.97609157 & 10486.94101169 & 9695.41660955 & 6954.00625290 \\
\hline & LX-PM-GSA & 1253.92122313 & 18657.37559197 & 5168.20300469 & 6086.43898631 & 3980.37550516 \\
\hline 3 & GSA & $\mathbf{0 . 0 0 0 0 0 0 0 0}$ & 646.55249364 & 79.52679031 & 106.50385531 & 112.97962917 \\
\hline & LX-GSA & $\mathbf{0 . 0 0 0 0 0 0 0 0}$ & 0.00247129 & 0.00002745 & 0.00026217 & 0.00054524 \\
\hline & PM-GSA & 0.18889025 & 679.73460278 & 43.67145920 & 86.62865794 & 132.31660846 \\
\hline & LX-PM-GSA & $\mathbf{0 . 0 0 0 0 0 0 0 0}$ & $\mathbf{0 . 0 0 0 0 0 0 0 0}$ & $\mathbf{0 . 0 0 0 0 0 0 0 0}$ & $\mathbf{0 . 0 0 0 0 0 0 0 0}$ & $\mathbf{0 . 0 0 0 0 0 0 0 0}$ \\
\hline
\end{tabular}




\begin{tabular}{|c|c|c|c|c|c|c|}
\hline 4 & GSA & 0.00000000 & 0.00000000 & 0.00000000 & 0.00000000 & 0.00000000 \\
\hline & LX-GSA & 0.00000000 & 0.00000000 & 0.00000000 & 0.00000000 & 0.00000000 \\
\hline & PM-GSA & 0.00000000 & 0.00000000 & 0.00000000 & 0.00000000 & 0.00000000 \\
\hline & LX-PM-GSA & 0.00000000 & 0.00000000 & 0.00000000 & 0.00000000 & 0.00000000 \\
\hline \multirow[t]{4}{*}{5} & GSA & 19.99996146 & 20.05173018 & 19.99999968 & 20.00110380 & 0.00726033 \\
\hline & LX-GSA & 19.99725077 & 19.99997369 & 19.99949381 & 19.99925684 & 0.00065387 \\
\hline & PM-GSA & 19.99980577 & 20.02234066 & 19.99999920 & 20.00055467 & 0.00316249 \\
\hline & LX-PM-GSA & 19.99857877 & 19.99999993 & 19.99974857 & 19.99963320 & 0.00040356 \\
\hline \multirow[t]{4}{*}{6} & GSA & 4.57635183 & 13.72905548 & 9.22905548 & 9.10253310 & 1.99106089 \\
\hline & LX-GSA & 9.15270369 & 18.38176705 & 15.07635187 & 14.16880086 & 2.40204131 \\
\hline & PM-GSA & 6.00000006 & 12.30540735 & 9.15270371 & 9.19749369 & 1.84704731 \\
\hline & LX-PM-GSA & 9.00001434 & 23.07537646 & 14.00783663 & 14.22331542 & 2.75445731 \\
\hline \multirow[t]{4}{*}{7} & GSA & 0.00000000 & 0.00000000 & 0.00000000 & 0.00000000 & 0.00000000 \\
\hline & LX-GSA & 0.00000000 & 0.03192282 & 0.00986467 & 0.01023446 & 0.00851100 \\
\hline & PM-GSA & 0.00000000 & 0.00985728 & 0.00000000 & 0.00019329 & 0.00138029 \\
\hline & LX-PM-GSA & 0.00000000 & 0.03685749 & 0.00985728 & 0.01139410 & 0.01057767 \\
\hline \multirow[t]{4}{*}{8} & GSA & 68.53666156 & 126.27343656 & 103.47552508 & 104.78988762 & 11.67724409 \\
\hline & LX-GSA & 51.73782059 & 99.49565854 & 75.61674714 & 76.39711054 & 12.02590023 \\
\hline & PM-GSA & 78.60165967 & 121.43291933 & 98.50073484 & 99.94572346 & 10.91987546 \\
\hline & LX-PM-GSA & 44.77312230 & 101.48562717 & 66.66217114 & 66.95479011 & 12.14383033 \\
\hline \multirow[t]{4}{*}{9} & GSA & 76.61164543 & 121.38466679 & 99.49564320 & 99.90528666 & 11.62551089 \\
\hline & LX-GSA & 99.49559777 & 175.11193937 & 147.25328298 & 146.06327599 & 16.52580719 \\
\hline & PM-GSA & $\mathbf{5 8 . 7 0 2 5 0 8 7 6}$ & 120.38954561 & 94.52084791 & 94.32574852 & 11.28124400 \\
\hline & LX-PM-GSA & 95.51578677 & 171.13218970 & 136.30875350 & 135.17732143 & 18.05337708 \\
\hline \multirow[t]{4}{*}{10} & GSA & 1667.93386404 & 3621.63461825 & 2371.00591394 & 2412.53373892 & 427.57340393 \\
\hline & LX-GSA & 475.24564602 & 1249.80825699 & 599.06359377 & 671.47966058 & 148.19107197 \\
\hline & PM-GSA & 1666.75085536 & 3403.34488561 & 2399.13786177 & 2465.80096772 & 378.46032943 \\
\hline & LX-PM-GSA & 243.92021300 & $\mathbf{9 3 3 . 5 6 5 6 7 5 1 5}$ & $\mathbf{5 9 7 . 0 4 1 7 3 3 1 0}$ & $\mathbf{5 9 5 . 4 5 5 1 1 1 0 3}$ & 141.36495066 \\
\hline \multirow[t]{4}{*}{11} & GSA & 1159.91225293 & 3647.65955754 & 2439.25781339 & 2464.59361529 & 492.02522169 \\
\hline & LX-GSA & 2461.31880669 & 4438.09829440 & 3464.36909069 & 3509.10443232 & 478.07071489 \\
\hline & PM-GSA & 1376.20249902 & 3408.39155647 & 2482.46529013 & 2464.05810836 & 447.53198836 \\
\hline & LX-PM-GSA & 2222.77037633 & 4212.66619676 & 3408.79639568 & 3363.34204378 & 473.58205175 \\
\hline \multirow[t]{4}{*}{12} & GSA & 0.00000000 & 0.00052441 & 0.00000000 & 0.00001029 & 0.00007343 \\
\hline & LX-GSA & 0.00020424 & 0.01939696 & 0.00277420 & 0.00369199 & 0.00354131 \\
\hline & PM-GSA & 0.00000000 & 0.00060942 & 0.00000000 & 0.00002032 & 0.00010318 \\
\hline & LX-PM-GSA & 0.00060626 & 0.01221719 & 0.00374224 & 0.00447374 & 0.00295698 \\
\hline \multirow[t]{4}{*}{13} & GSA & 0.09976242 & 0.18708589 & 0.14987836 & 0.15078579 & 0.01715804 \\
\hline & LX-GSA & 0.04064954 & 0.15821064 & 0.07794236 & 0.07757955 & 0.02060423 \\
\hline & PM-GSA & 0.10933441 & 0.18609381 & 0.15120802 & 0.14978877 & 0.01910357 \\
\hline & LX-PM-GSA & 0.04169572 & 0.17293137 & 0.09177251 & 0.09525115 & 0.02921056 \\
\hline 14 & GSA & 0.23434911 & 0.47528128 & 0.38864801 & 0.37442219 & 0.05273033 \\
\hline
\end{tabular}




\begin{tabular}{|c|c|c|c|c|c|c|}
\hline & LX-GSA & 0.14037486 & 0.39819757 & 0.28568495 & 0.27746557 & 0.05398024 \\
\hline & PM-GSA & 0.29028381 & 0.47709730 & 0.37748020 & 0.38200794 & 0.04979223 \\
\hline & LX-PM-GSA & 0.11566866 & 0.32604107 & 0.22264482 & 0.21679213 & 0.05590145 \\
\hline \multirow[t]{4}{*}{15} & GSA & 1.04896756 & 5.79565772 & 4.35697246 & 4.10927610 & 1.12304503 \\
\hline & LX-GSA & 1.74328553 & 5.53130445 & 3.18826501 & 3.27537153 & 0.67176970 \\
\hline & PM-GSA & 1.16054715 & 6.11721215 & 4.41401616 & 4.20810756 & 1.21403970 \\
\hline & LX-PM-GSA & 2.12676995 & 5.02183146 & 3.09948777 & 3.23239395 & 0.73837986 \\
\hline \multirow[t]{4}{*}{16} & GSA & 11.81623634 & 13.69412500 & 13.03803058 & 12.96334854 & 0.37823237 \\
\hline & LX-GSA & 10.27464066 & 12.31243680 & 11.21481973 & 11.24991437 & 0.49636110 \\
\hline & PM-GSA & 12.06885161 & 13.12122677 & 12.49424675 & 12.50886129 & 0.25831868 \\
\hline & LX-PM-GSA & 9.87550407 & 12.32744923 & 11.12193307 & 11.13323947 & 0.55466157 \\
\hline \multirow[t]{4}{*}{17} & GSA & 1078.11634461 & 3755.76346560 & 2318.70315070 & 2324.59615807 & 638.03905918 \\
\hline & LX-GSA & 610.09503494 & 2715.57037870 & 1711.01753382 & 1671.62088089 & 489.20009532 \\
\hline & PM-GSA & 993.80496243 & 3639.58897556 & 2091.18866963 & 2122.01756437 & 558.10996058 \\
\hline & LX-PM-GSA & 761.733338007 & 2428.81166666 & 1460.41847784 & 1491.68952228 & 426.53067088 \\
\hline \multirow[t]{4}{*}{18} & GSA & 78.51065140 & 12477.08396251 & 521.95066594 & 1580.65267026 & 2421.85287250 \\
\hline & LX-GSA & 63.38554167 & 2994.27314165 & 336.53141175 & 573.97716106 & 657.09140861 \\
\hline & PM-GSA & 72.15482657 & 5490.80679303 & 634.05660257 & 1008.67087161 & 1182.06409955 \\
\hline & LX-PM-GSA & 53.14238414 & 5862.22234785 & 350.46063729 & 784.15605529 & 1197.85440465 \\
\hline \multirow[t]{4}{*}{19} & GSA & 3.52412568 & 9.02844169 & 4.49735257 & 5.24139961 & 1.19824924 \\
\hline & LX-GSA & 4.63714278 & 12.23234545 & 8.47692794 & 8.28954404 & 1.83204877 \\
\hline & PM-GSA & 3.54121646 & 8.94920732 & 4.44507522 & 5.15609836 & 1.23648997 \\
\hline & LX-PM-GSA & 3.67310804 & 69.95055911 & 7.65095504 & 8.78918877 & 8.96739718 \\
\hline \multirow[t]{4}{*}{20} & GSA & 759.94272244 & 15192.47668987 & 6009.45329027 & 6228.32841428 & 3733.98980045 \\
\hline & LX-GSA & 37.18133981 & 214.35599791 & 119.07986158 & 121.72250335 & 42.06837478 \\
\hline & PM-GSA & 1099.73256941 & 9305.13814381 & 3977.54398163 & 4143.85496757 & 2003.19563101 \\
\hline & LX-PM-GSA & 41.73302583 & 400.77557478 & 158.81643959 & 184.54238280 & 96.44981041 \\
\hline \multirow[t]{4}{*}{21} & GSA & 758.25532203 & 5257.42945587 & 2168.55115332 & 2472.81246136 & 1050.87524021 \\
\hline & LX-GSA & 216.42581693 & 1659.49722326 & 929.39057682 & 934.00622980 & 332.67946327 \\
\hline & PM-GSA & 1020.95481081 & 6191.20253391 & 2467.22366450 & 2895.51572571 & 1390.04939550 \\
\hline & LX-PM-GSA & 205.05547038 & 1900.52613358 & 604.75327244 & 615.55510029 & 277.39869836 \\
\hline \multirow[t]{4}{*}{22} & GSA & 395.38741943 & 1551.12247709 & 963.53248593 & 940.78655977 & 241.61046434 \\
\hline & LX-GSA & 409.18613370 & 1499.36979589 & 976.05864391 & 969.78032381 & 239.85373982 \\
\hline & PM-GSA & 132.46650534 & 753.36120642 & 492.48873435 & 480.17298341 & 136.21855464 \\
\hline & LX-PM-GSA & 48.44324611 & 696.88441082 & 403.18179616 & 394.64915810 & 151.63184399 \\
\hline \multirow[t]{4}{*}{23} & GSA & 200.00000002 & 315.24410219 & 315.24410219 & 270.05033663 & 56.82565670 \\
\hline & LX-GSA & 200.00000006 & 315.24410219 & 315.24410219 & 306.20534908 & 31.29158364 \\
\hline & PM-GSA & 200.00000006 & 315.24410219 & 315.24410219 & 267.79064837 & 57.28209499 \\
\hline & LX-PM-GSA & 200.00000013 & 315.24410219 & 315.24410219 & 312.98441391 & 16.13740209 \\
\hline \multirow[t]{3}{*}{24} & GSA & 200.00468387 & 200.01238616 & 200.00771603 & 200.00776655 & 0.00157987 \\
\hline & LX-GSA & 200.00028182 & 200.00120350 & 200.00062433 & 200.00064084 & 0.00021527 \\
\hline & PM-GSA & 200.00522246 & 200.01124244 & 200.00754599 & 200.00784071 & 0.00150095 \\
\hline
\end{tabular}




\begin{tabular}{|c|c|c|c|c|c|c|}
\hline & LX-PM-GSA & 200.00028594 & 222.14359753 & 200.00062856 & 200.43482446 & 3.10063299 \\
\hline \multirow[t]{4}{*}{25} & GSA & 200.00000000 & 200.00000000 & 200.00000000 & 200.00000000 & 0.00000000 \\
\hline & LX-GSA & 200.00000000 & 200.00000000 & 200.00000000 & 200.00000000 & 0.00000000 \\
\hline & PM-GSA & 200.00000000 & 200.00000000 & 200.00000000 & 200.00000000 & 0.00000000 \\
\hline & LX-PM-GSA & 200.00000000 & 207.32369984 & 200.00000000 & 200.28604969 & 1.42997448 \\
\hline \multirow[t]{4}{*}{26} & GSA & 100.14308006 & 200.01838846 & 200.00000000 & 162.03781555 & 47.44793832 \\
\hline & LX-GSA & 100.08298010 & 200.01324490 & 200.00000000 & 194.12382381 & 23.73970317 \\
\hline & PM-GSA & 100.13427554 & 200.00000000 & 104.52495733 & 105.43893355 & 13.83167487 \\
\hline & LX-PM-GSA & 100.00969865 & 200.00000000 & 100.43906329 & 110.15169914 & 29.91746209 \\
\hline \multirow[t]{4}{*}{27} & GSA & 388.58112453 & 2077.90627126 & 587.67863921 & 780.28633164 & 490.68424776 \\
\hline & LX-GSA & 400.00000000 & 976.06514967 & 723.70546657 & 654.50083590 & 200.65385776 \\
\hline & PM-GSA & 354.43179111 & 1534.96766826 & 601.42024393 & 645.36935330 & 262.84432600 \\
\hline & LX-PM-GSA & 400.45420214 & 1036.64123419 & 691.31617303 & 657.22815206 & 213.33414389 \\
\hline \multirow[t]{4}{*}{28} & GSA & 504.31277959 & 2927.33430986 & 1533.45627769 & 1584.90378500 & 554.70660877 \\
\hline & LX-GSA & 2032.32747548 & 4536.94969994 & 3426.99274766 & 3432.80831978 & 615.80689316 \\
\hline & PM-GSA & 813.34340128 & 2830.60805816 & 1578.10688336 & 1603.80119960 & 443.58661929 \\
\hline & LX-PM-GSA & 919.83825703 & 3937.63153437 & 1795.14457078 & 1988.71504049 & 790.43167568 \\
\hline \multirow[t]{4}{*}{29} & GSA & 200.02436494 & 1832.21169383 & 200.03267989 & 360.87781241 & 448.20920885 \\
\hline & LX-GSA & 200.05690077 & 1609.41675617 & 978.84816878 & 777.60337082 & 493.76020544 \\
\hline & PM-GSA & 200.06802124 & 1759.63215536 & 200.08076297 & 280.86980842 & 329.23817674 \\
\hline & LX-PM-GSA & 1004.82581376 & 8664467.69023 & 1680.20958150 & 1834172.46227 & 3528541.15112 \\
\hline \multirow[t]{4}{*}{30} & GSA & 909.32711677 & 2608.98973924 & 1708.67321798 & 1723.16276031 & 470.55457654 \\
\hline & LX-GSA & 955.16066664 & 2330.36142424 & 1533.70227729 & 1562.31770720 & 367.88483552 \\
\hline & PM-GSA & 1018.42795975 & 2940.01759776 & 1793.89635516 & 1854.01807034 & 480.96475034 \\
\hline & LX-PM-GSA & 815.19832891 & 3135.76326682 & 1717.80733718 & 1764.73445760 & 511.45347789 \\
\hline
\end{tabular}

Further, according to the requirement of Liang et al [38] the computational complexity of the four algorithms is calculated and reported in Table 7 . From this table it can be observed that the computational complexity of GSA is the minimum. Therefore, it may be concluded that the performance of LX-PM-GSA is best but at the cost of slightly higher computational complexity.

Table 7. Computational Complexity of the Algorithms Considered

\begin{tabular}{|c|c|c|c|c|}
\hline Algo. & $\mathrm{T}_{0}$ & $\mathrm{~T}_{1}$ & $\hat{\mathrm{T}}_{2}$ & $\left(\hat{\mathrm{T}}_{2}-\mathrm{T}_{1}\right) / \mathrm{T}_{0}$ \\
\hline GSA & 0.221163 & 127.6977 & $\mathbf{9 0 6 . 3 3 9 5}$ & $\mathbf{3 5 2 0 . 6 6 9 4}$ \\
\hline LX-GSA & 0.221163 & 131.3610 & $\begin{array}{c}917.5944 \\
3\end{array}$ & 3554.9950 \\
\hline PM-GSA & 0.221163 & 129.9013 & 916.3018 & 3555.7507 \\
\hline $\begin{array}{c}\text { LX-PM- } \\
\text { GSA }\end{array}$ & 0.221163 & $\mathbf{1 2 6 . 6 4 8 0}$ & 922.7007 & 3599.3936 \\
\hline
\end{tabular}

\section{CONCLUSIONS}

The Gravitational Search Algorithm was introduced based on the laws of physics. In spite of its advantage of being a memory less nature inspired optimization technique, it has a major drawback of slow convergence during later iterations and poor performance on multi modal problems. With an objective to improve its performance the Laplace Crossover and Power Mutation, earlier proposed for real coded genetic algorithms by one of the authors are used to hybridize Gravitational Search Algorithm in three different ways. In the first hybrid version the Laplace Crossover is applied to the best and a randomly selected particle after the iteration of Gravitational Search Algorithm is over. In the second hybrid version after each iteration of Gravitational Search Algorithm the Power Mutation is applied. In the third version both the Laplace a Crossover and Power Mutation are applied at the end of each iteration. The original Gravitational Search Algorithm along with the three proposed hybrid versions are programmed in MATLAB and used to solve a variety of unimodal and multi modal problems having low and high dimensionality. The numerical results are analysed and it is concluded that the hybrid version incorporating both the Laplace Crossover and Power Mutation surpasses the original Gravitational Search Algorithm as well as the other two proposed variants on a variety of benchmark optimization problems including the CEC 2014 benchmark problems containing high dimensional 
unimodal functions, high dimensional multi modal functions and low dimensional multi modal functions.

\section{APPENDIX A. BENCHMARK TEST FUNCTIONS}

\section{Sphere}

$$
F_{1}(x)=\sum_{i=1}^{n} x_{i}^{2},-100 \leq x_{i} \leq 100, \min \left(F_{1}\right)=F_{1}(0, \ldots, 0)=0 .
$$

2. Schwefel's Problem 2.22

$$
\begin{aligned}
& F_{2}(x)=\sum_{i=1}^{n}\left|x_{i}\right|+\prod_{i=1}^{n}\left|x_{i}\right|, \quad-10 \leq x_{i} \leq 10, \\
& \min \left(F_{2}\right)=F_{2}(0, \ldots, 0)=0 .
\end{aligned}
$$

3. Schwefel's Problem 1.2

$$
\begin{aligned}
& F_{3}(x)=\sum_{i=1}^{n}\left(\sum_{j=1}^{i} x_{j}\right)^{2}, \quad-100 \leq x_{i} \leq 100, \\
& \min \left(F_{3}\right)=F_{3}(0, \ldots, 0)=0 .
\end{aligned}
$$

4. Schwefel's Problem 2.21

$$
\begin{aligned}
& F_{4}(x)=\max \left\{\left|x_{i}\right|, 1 \leq i \leq 30\right\}, \quad-100 \leq x_{i} \leq 100, \\
& \min \left(F_{4}\right)=F_{4}(0, \ldots, 0)=0 .
\end{aligned}
$$

5. Generalized Rosenbrock's function

$$
\begin{aligned}
& F_{5}(x)=\sum_{i=1}^{n-1}\left[100\left(x_{i+1}-x_{i}^{2}\right)^{2}+\left(x_{i}-1\right)^{2}\right], \quad-30 \leq x_{i} \leq 30, \\
& \min \left(F_{5}\right) \stackrel{=}{=} F_{5}(1, \ldots, 1)=0 .
\end{aligned}
$$

6. Step function

$$
\begin{aligned}
& F_{6}(x)=\sum_{i=1}^{n}\left(\left\lfloor x_{i}+0.5\right\rfloor\right)^{2}, \quad-100 \leq x_{i} \leq 100, \\
& \min \left(F_{6}\right)=F_{6}(0, \ldots, 0)=0 .
\end{aligned}
$$

\section{Quartic function i.e Noise}

$$
F_{7}(x)=\sum_{i=1}^{n} i x_{i}^{4}+\operatorname{random}[0,1), \quad-1.28 \leq x_{i} \leq 1.28,
$$$$
\min \left(F_{7}\right) \stackrel{i=1}{=} F_{7}(0, \ldots, 0)=0 .
$$

8. Generalized Schwefel's Problem 2.26

$F_{8}(x)=\sum_{i=1}^{n}\left(-x_{i} \sin \sqrt{\left|x_{i}\right|}\right), \quad-500 \leq x_{i} \leq 500$,

$\min \left(F_{8}\right) \stackrel{i=1}{=} F_{8}(420.9687, \ldots, 420.9687)=-12,569.48$.

9. Generalized Rastrigin's function

$$
F_{9}(x)=\sum_{i=1}^{n}\left[x_{i}^{2}-10 \cos \left(2 \pi x_{i}\right)+10\right], \quad-5.12 \leq x_{i} \leq 5.12,
$$$$
\min \left(F_{9}\right) \stackrel{i=1}{=} F_{9}(0, \ldots, 0)=0 .
$$

10. Ackley's function

$$
\begin{aligned}
& F_{10}(x)=-20 \exp \left(-0.2 \sqrt{\frac{1 \sum_{i=1}^{n} x_{i}^{2}}{n}}\right)-\exp \left(\frac{1}{n} \sum_{i=1}^{n} \cos 2 \pi x_{i}\right)+20+e, \\
& -32 \leq x_{i} \leq 32, \quad \min \left(F_{10}\right)=F_{10}(0, \ldots, 0)=0 .
\end{aligned}
$$

11. Generalized Griewank’s function

$$
\begin{aligned}
& F_{11}(x)=\frac{1}{4000} \sum_{i=1}^{n} x_{i}^{2}-\prod_{i=1}^{n} \cos \left(\frac{x_{i}}{\sqrt{i}}\right)+1, \\
& -600 \leq x_{i} \leq 600 \quad \min \left(F_{11}\right)=F_{11}(0, \ldots, 0)=0 .
\end{aligned}
$$

12. Generalized Penalized function 1

$$
\begin{aligned}
F_{12}(x)= & \frac{\pi}{n}\left\{\begin{array}{l}
10 \sin ^{2}\left(\pi y_{1}\right)+\sum_{i=1}^{n-1}\left(y_{i}-1\right)^{2}\left[1+10 \sin ^{2}\left(\pi y_{i+1}\right)\right] \\
+\left(y_{n}-1\right)^{2}
\end{array}\right\} \\
& +\sum_{i=1}^{n} u\left(x_{i}, 10,100,4\right),
\end{aligned}
$$

Where

$$
\begin{aligned}
& y_{i}=1+\frac{1}{4}\left(x_{i}+1\right), \quad u\left(x_{i}, a, k, m\right)=\left\{\begin{array}{ll}
k\left(x_{i}-a\right)^{m} & x_{i}>a \\
0 & -a<x_{i}<a \\
k\left(-x_{i}-a\right)^{m} & x_{i}<-a
\end{array},\right. \\
& -50 \leq x_{i} \leq 50 \quad \min \left(F_{12}\right)=F_{12}(1, \ldots, 1)=0 .
\end{aligned}
$$

13. Generalized Penalized function 2

$$
\begin{aligned}
& F_{13}(x)=0.1\left(\begin{array}{l}
\sin ^{2}\left(3 \pi x_{1}\right)+\sum_{i=1}^{n-1}\left(x_{i}-1\right)^{2}\left[1+\sin ^{2}\left(3 \pi x_{i+1}\right)\right] \\
+\left(x_{n}-1\right)^{2}\left[1+\sin ^{2}\left(2 \pi x_{n}\right)\right]
\end{array}\right) \\
&+\sum_{i=1}^{n} u\left(x_{i}, 5,100,4\right), \\
&-50 \leq x_{i} \leq 50 \quad \min \left(F_{13}\right)=F_{13}(1, \ldots, 1)=0 .
\end{aligned}
$$

14. Fifth function of De Jong

$$
\begin{aligned}
& F_{14}(x)=\left\{0.002+\sum_{j=1}^{25}\left[j+\left(x_{1}-a_{1 j}\right)^{6}+\left(x_{2}-a_{2 j}\right)^{6}\right]^{-1}\right\}^{-1}, \\
& -65.53 \leq x_{1}, x_{2} \leq 65.53, \min \left(F_{14}\right)=F_{14}(-32,32)=1
\end{aligned}
$$

15. Kowalik function

$$
\begin{aligned}
F_{15}(x) & =\sum_{i=1}^{11}\left[a_{i}-\frac{x_{1}\left(b_{i}^{2}+b_{i} x_{2}\right)}{b_{i}^{2}+b_{i} x_{3}+x_{4}}\right]^{2} \quad-5 \leq x_{1}, x_{2}, x_{3}, x_{4} \leq 5 \\
\min \left(F_{15}\right) & =F_{15}(0.192833,0.190836,0.123117,0.135866) \\
& =0.0003075
\end{aligned}
$$

16. Camel Back-6 Hump Problem

$F_{16}(x)=4 x_{1}^{2}-2.1 x_{1}^{4}+\frac{1}{3} x_{1}^{6}+x_{1} x_{2}-4 x_{2}^{2}+4 x_{2}^{4}$,

$-5 \leq x_{1}, x_{2} \leq 5, \min \left(F_{16}\right)=F_{16}\left(x^{*}\right)=-1.0316285$, $x^{*}=(0.089842,-0.712656),(-0.089842,0.712656)$

17. Branin function

$$
\begin{aligned}
& F_{17}(x)=\left(x_{2}-\frac{5.1}{4 \pi^{2}} x_{1}^{2}+\frac{5}{\pi} x_{1}-6\right)^{2}+10\left(1-\frac{1}{8 \pi}\right) \cos x_{1}+10, \\
& -5 \leq x_{1} \leq 10 \quad 0 \leq x_{2} \leq 15, \min \left(F_{17}\right)=F_{17}\left(x^{*}\right)=\frac{5}{4 \pi}, \\
& x^{*}=(-\pi, 12.275),(\pi, 2.275),(3 \pi, 2.475)
\end{aligned}
$$

18. Goldstein-Price's function

$$
\begin{aligned}
& F_{18}(x)=\left[1+\left(x_{1}+x_{2}+1\right)^{2}\left(19-14 x_{1}+3 x_{1}^{2}-14 x_{2}+6 x_{1} x_{2}+3 x_{2}^{2}\right)\right] \\
& \quad\left[30+\left(2 x_{1}-3 x_{2}\right)^{2}\left(18-32 x_{1}+12 x_{1}^{2}+48 x_{2}-36 x_{1} x_{2}+27 x_{2}^{2}\right)\right] \\
& -5 \leq x_{1}, x_{2} \leq 5 \quad \min \left(F_{18}\right)=F_{18}(0,-1)=3 .
\end{aligned}
$$

19. Hartman 3 function 
$F_{19}(x)=-\sum_{i=1}^{4} c_{i} \exp \left[-\sum_{j=1}^{3} a_{i j}\left(x_{j}-p_{i j}\right)^{2}\right], \quad 0 \leq x_{j} \leq 1, j \in\{1,2,3\}$
$\min \left(F_{19}\right)=F_{19}(0.1140,0.556,0.852) \approx-3.862747$

20. Hartman 6 function

$$
\begin{aligned}
F_{20}(x)= & -\sum_{i=1}^{4} c_{i} \exp \left[-\sum_{j=1}^{6} a_{i j}\left(x_{j}-p_{i j}\right)^{2}\right], \\
0 \leq x_{j} \leq 1, j \in\{1,2, \ldots, 6\} & \\
\min \left(F_{20}\right) & =F_{20}\left(\begin{array}{c}
0.201690,0.150011,0.476874, \\
0.275332,0.311652,0.657301
\end{array}\right) \\
\approx & -3.322368
\end{aligned}
$$

\section{Shekel function}

$$
\begin{aligned}
& F_{21}(x)=-\sum_{i=1}^{5}\left[\left(x-a_{i}\right)\left(x-a_{i}\right)^{T}+c_{i}\right]^{-1}, \\
& 0 \leq x_{i} \leq 10 \quad i \in\{1,2,3,4\} \min \left(F_{21}\right)=-10.1532
\end{aligned}
$$

22. Shekel function

$$
\begin{aligned}
& F_{22}(x)=-\sum_{i=1}^{7}\left[\left(x-a_{i}\right)\left(x-a_{i}\right)^{T}+c_{i}\right]^{-1}, \\
& 0 \leq x_{i} \leq 10 \quad i \in\{1,2,3,4\} \min \left(F_{22}\right)=-10.4028
\end{aligned}
$$

23. Shekel function

$$
\begin{aligned}
& F_{23}(x)=-\sum_{i=1}^{10}\left[\left(x-a_{i}\right)\left(x-a_{i}\right)^{T}+c_{i}\right]^{-1}, \\
& 0 \leq x_{i} \leq 10 \quad i \in\{1,2,3,4\} \quad \min \left(F_{23}\right)=-10.5363
\end{aligned}
$$

\section{APPENDIX B.}

\begin{tabular}{|c|c|c|c|c|c|c|c|}
\hline$i$ & \multicolumn{6}{|c|}{$a_{i j}, j=1,2,3,4,5,6$} & $c_{i}$ \\
\hline 1 & 10 & 3 & 17 & 3.5 & 1.7 & 8 & 1 \\
\hline 2 & 0.05 & 10 & 17 & 0.1 & 8 & 14 & 1.2 \\
\hline 3 & 3 & 3.5 & 1.7 & 10 & 17 & 8 & 3 \\
\hline 4 & 17 & 8 & 0.05 & 10 & 0.1 & 14 & 3.2 \\
\hline
\end{tabular}

Table $\mathrm{B}_{1} \cdot a_{i j}$ in $F_{14}$



Table $\mathrm{B}_{2} . \boldsymbol{a}_{\boldsymbol{i}}$ and $\boldsymbol{b}_{\boldsymbol{i}}$ in $\boldsymbol{F}_{15}$

\begin{tabular}{|c|c|c|c|c|c|}
\hline$i$ & \multicolumn{4}{|c|}{$a_{i j}, j=1,2,3,4$} & $c_{i}$ \\
\hline 1 & 4 & 4 & 4 & 4 & 0.1 \\
\hline 2 & 1 & 1 & 1 & 1 & 0.2 \\
\hline 3 & 8 & 8 & 8 & 8 & 0.2 \\
\hline 4 & 6 & 6 & 6 & 6 & 0.4 \\
\hline 5 & 3 & 7 & 3 & 7 & 0.4 \\
\hline 6 & 2 & 9 & 2 & 9 & 0.6 \\
\hline 7 & 5 & 5 & 3 & 3 & 0.3 \\
\hline 8 & 8 & 1 & 8 & 1 & 0.7 \\
\hline 9 & 6 & 2 & 6 & 2 & 0.5 \\
\hline 10 & 7 & 3.6 & 7 & 3.6 & 0.5 \\
\hline
\end{tabular}

\begin{tabular}{|c|l|l|l|l|l|l|}
\hline$i$ & 1 & 2 & 3 & 4 & 5 & 6 \\
\hline$a_{i}$ & 0.1957 & 0.1947 & 0.1735 & 0.1600 & 0.0844 & 0.0627 \\
$b_{i}^{-1}$ & 0.25 & 0.5 & 1 & 2 & 4 & 6 \\
\hline$i$ & 7 & 8 & 9 & 10 & 11 & - \\
\hline$a_{i}$ & 0.0456 & 0.0342 & 0.0323 & 0.0235 & 0.0246 & - \\
$b_{i}^{-1}$ & 8 & 10 & 12 & 14 & 16 & - \\
\hline
\end{tabular}

Table $\mathrm{B}_{3} \cdot a_{i j}$ and $c_{i}$ in $F_{19}$

\begin{tabular}{|c|c|c|c|c|}
\hline$i$ & \multicolumn{3}{|c|}{$\boldsymbol{a}_{i j}, \boldsymbol{j}=\mathbf{1 , 2 , 3}$} & $\boldsymbol{c}_{\boldsymbol{i}}$ \\
\hline 1 & 3 & 10 & 30 & 1 \\
2 & 0.1 & 10 & 35 & 1.2 \\
3 & 3 & 10 & 30 & 3 \\
4 & 0.1 & 10 & 35 & 3.2 \\
\hline
\end{tabular}

Table $\mathrm{B}_{4} \cdot p_{i j}$ in $_{F_{19}}$

\begin{tabular}{|l|l|l|l|}
\hline$i$ & \multicolumn{3}{|c|}{$p_{i j}, j=1,2,3$} \\
\hline 1 & 0.3689 & 0.1170 & 0.2673 \\
2 & 0.4699 & 0.4387 & 0.7470 \\
3 & 0.1091 & 0.8732 & 0.5547 \\
4 & 0.03815 & 0.5743 & 0.8828 \\
\hline
\end{tabular}

Table $\mathrm{B}_{5} \cdot a_{i j}$ and $c_{i}$ in $F_{20}$

Table $\mathrm{B}_{6 \cdot} p_{i j}$ in $F_{20}$

\begin{tabular}{|c|c|c|c|c|c|c|}
\hline$i$ & \multicolumn{6}{|c|}{$p_{i j}, j=1,2,3,4,5,6$} \\
\hline 1 & 0.1312 & 0.1696 & 0.5569 & 0.0124 & 0.8283 & 0.5886 \\
2 & 0.2329 & 0.4135 & 0.8307 & 0.3736 & 0.1004 & 0.9991 \\
3 & 0.2348 & 0.1451 & 0.3522 & 0.2883 & 0.3047 & 0.6650 \\
4 & 0.4047 & 0.8828 & 0.8732 & 0.5743 & 0.1091 & 0.0381 \\
\hline
\end{tabular}

Table $\mathrm{B}_{7} \cdot a_{i j}$ and $c_{i}$ in $F_{21}, F_{22}, F_{23}$

\section{ACKNOWLEDGEMENT}

The first author would like to thank Council for Scientific and Industrial Research (CSIR), New Delhi, India, for providing him the financial support vide grant number 09/143(0824)/2012-EMR-I and ICC, Indian Institute of Technology Roorkee, Roorkee for computational facility.

\section{REFERENCES}

[1] M. Dorigo, G.D. Caro, "Ant colony optimization: a new meta-heuristic," in proceeding of the 1999 Congress on Evolutionary Computation, Washington, DC, USA, 1999, pp. 1470-1478.

[2] D. Karaboga, B. Basturk, "Artificial bee colony (ABC) optimization algorithm for solving constrained optimization problems," Foundations of Fuzzy Logic and Soft Computing, Springer Berlin Heidelberg, 2007, pp. 789-798.

[3] M. Basu, "Artificial immune system for dynamic economic dispatch," International Journal of Electrical Power \& Energy Systems, 2011, 33(1) pp. 131-136.

[4] S. Das, A. Biswas, S. Dasgupta, A. Abraham, "Bacterial foraging optimization algorithm: theoretical foundations, analysis, and applications," In Foundations of Computational Intelligence, Springer Berlin Heidelberg, vol. 3, 2009, pp. 23-55.

[5] R. Storn, K. Price, "Differential evolution-a simple and efficient heuristic for global optimization over continuous spaces," Journal of global optimization, 11(4), 1997, pp. 341-359.

[6] T. Back, Evolutionary Algorithms in Theory and Practice: Evolution Strategies, Evolutionary Programming, Genetic Algorithms, Oxford Univ. Press, New York, USA 1996.

[7] K. N. Krishnanand, D. Ghose, "Glowworm swarm optimisation: a new method for optimising multi-modal 
functions," International Journal of Computational Intelligence Studies, 1(1), 2009, pp. 93-119.

[8] A. Singh, K. Deep, "How Improvements in Glowworm Swarm Optimization Can Solve Real-Life Problems," In Proceedings of Fourth International Conference on Soft Computing for Problem Solving, Springer India, 2015, pp. 275-287.

[9] J. Kennedy, Particle swarm optimization, In Encyclopedia of Machine Learning, Springer US, 2010, pp. 760-766.

[10] S. Kirkpatrick, C.D. Gelatt, M.P. Vecchi, Optimization by Simulated annealing, Science 220 (4598), 1983, pp. 671680.

[11] Y. Wang, J. Zeng, Z. Cui, X. He, "A novel constraint multi-objective artificial physics optimization algorithm and its convergence," Int. J. Innovat. Comput. Appl. 3(2), 2011, pp. 61-70.

[12] L. Xie, Y. Tan, J. Zeng, Z. Cui, "The convergence analysis of artificial physics optimization algorithm," Int. J. Intell. Inform. Database Syst. 5 (6), 2011, pp. 536-555.

[13] R. A. Formato, "Central force optimization: a new nature inspired computational framework for multidimensional search and optimization," Nature Inspired Cooperative Strategies for Optimization (NICSO). Stud. Computa. Intell., 129, 2008, pp. 221-238.

[14] Z. W. Geem, J. H. Kim, G. V. Loganathan, "A new heuristic optimization algorithm: harmony search," Simulation 76 (2), 2001, pp. 60-68.

[15] Y. T. Hsiao, C. L. Chuang, J. A. Jiang, C. C. Chien, "A novel optimization algorithm: space gravitational optimization," In Systems, Man and Cybernetics, 2005 IEEE International Conference on 3, 2005, pp. 2323-2328.

[16] A. Biswas, K. K. Mishra, S. Tiwari, A. K. Misra, "Physics-inspired optimization algorithms: A survey," Journal of Optimization, 2013 < http://www.hindawi.com/journals/jopti/2013/438152/ >.

[17] E. Rashedi, H. Nezamabadi-Pour, S. Saryazdi, "GSA: a gravitational search algorithm," Information sciences, 179(13), 2009, pp. 2232-2248.

[18] S. Sarafrazi, H. Nezamabadi-pour, S. Saryazdi, "Disruption: A new operator in gravitational search algorithm,” Scientia Iranica, 18 (3), 2011, pp. 539-548.

[19] M. Doraghinejad, H. Nezamabadi-pour, "Black Hole: A New Operator for Gravitational Search Algorithm," International Journal of Computational Intelligence Systems, 7(5), 2014, pp. 809-826.

[20] M. S. Moghadam, H. Nezamabadi-Pour, M. M. Farsangi, "A Quantum Behaved Gravitational Search Algorithm," Intelligent Information Management 4, 2012, pp. 390-395.

[21] M. S. Moghadam, H. Nezamabadi-pour, "An improved quantum behaved gravitational search algorithm," 20th Iranian Conference on Electrical Engineering (ICEE2012), 2012, pp. 711-715.

[22] N. M. Sabri, M. Puteh, M. R. Mahmood, A review of gravitational search algorithm. Int. J. Advance. Soft Comput. Appl. 5, (3), 2013, pp. 1-39.

[23] R. E. Precup, R. C. David, E. M. Petriu, S. Preitl, M. B. Rădac, "Gravitational search algorithms in fuzzy control systems tuning," In Preprints of the 18th IFAC World Congress, 2011, pp. 13624-13629.

[24] G. Sahoo, "A Review on Gravitational Search Algorithm and its Applications to Data Clustering \& Classification," I.J. Intelligent Systems and Applications, 06, 2014, pp. 79-93.

[25] S. Gao, C. Vairappan, Y. Wang, Q. Cao, Z. Tang, "Gravitational search algorithm combined with chaos for unconstrained numerical optimization," Applied Mathematics and Computation, 231, 2014, pp. 48-62.
[26] E. Rashedi, H. Nezamabadi-Pour, S. Saryazdi, "BGSA: binary gravitational search algorithm," Natural Computing, 9 (3), 2010, pp. 727-745.

[27] S. Mirjalili, S. Z. M. Hashim, "A new hybrid PSOGSA algorithm for function optimization," International conference on Computer and information application (ICCIA2010), 2010, pp. 374-377.

[28] T. O. N. G. Chengyi, "Gravitational Search Algorithm Based on Simulated Annealing," Journal of Convergence Information Technology (JCIT) 9 (2) 2014, pp. 231-237.

[29] B. C. Xu, Y. Y. Zhang, "An improved gravitational search algorithm for dynamic neural network identification," International Journal of Automation and Computing, 11(4), 2014, pp. 434-440.

[30] B. Gu, F. Pan, "Modified Gravitational Search Algorithm with Particle Memory Ability and its Application," International Journal of Innovative Computing, Information and Control 9 (11), 2013, pp. 4531-4544.

[31] S. Jiang, Y. Wang, Z. Ji, "Convergence analysis and performance of an improved gravitational search algorithm," Applied Soft Computing 24, 2014, pp. 363384.

[32] A. Yadav, K. Deep, "Constrained Optimization Using Gravitational Search Algorithm," National Academy Science Letters 36 (5), 2013, pp. 527-534.

[33] A. Yadav, K. Deep, "A Novel Co-swarm Gravitational Search Algorithm for Constrained Optimization," Proceedings of the Third International Conference on Soft Computing for Problem Solving, Springer India, 2014, pp. 629-640.

[34] H. Nobahari, M. Nikusokhan, P. Siarry, "Non-dominated sorting gravitational search algorithm," In Proc. of the 2011 International Conference on Swarm Intelligence, 2011, pp. 1-10.

[35] H. R. Hassanzadeh, M. Rouhani, "A multi-objective gravitational search algorithm," Second International Conference on Computational Intelligence, Communication Systems and Networks (CICSyN), 2010, pp. 7-12.

[36] K. Deep, M. Thakur, "A new crossover operator for real coded genetic algorithms," Applied Mathematics and Computation, 188(1), 2007, pp. 895-911.

[37] K. Deep, M. Thakur, "A new mutation operator for real coded genetic algorithms," Applied mathematics and Computation, 193(1), 2007, pp. 211-230.

[38] J.J. Liang, B.Y.Qu, P.N Suganthan, "Problem Definitions and Evaluation Criteria for the CEC 2014. Special Session and Competition on Single Objective Real-Parameter Numerical Optimization,” Technical Report 201311, Computational Intelligence Laboratory, Zhengzhou University, Zhengzhou China and Technical Report, Nanyang Technological University, Singapore, December 2013.

\section{Authors' Profiles}



Mr. Amarjeet Singh, is a Research Scholar, with the Department of Mathematics, Indian Institute of Technology Roorkee, India. Born on July 2, 1987, he pursued B.Sc from C. C. S. University Meerut in 2006 and M.Sc from Indian Institute of Technology Roorkee in 2010. He was awarded 'Shyam \& Pushp Garg Annual Excellence Award' for outstanding academic, co-curricular and extra-curricular 
achievements in 2009. Presently, he is pursuing Ph.D. since August 7, 2012.

His areas of specialization are numerical optimization and their applications to engineering, science and industry. Currently his research interests are Nature Inspired Optimization Techniques, particularly, Gravitational Search Algorithm, Glowworm Optimization, and their applications to solve real life problems.

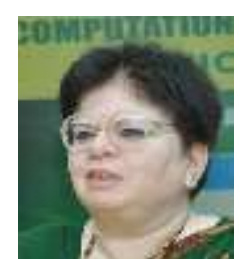

Dr. Kusum Deep, is a full Professor, with the Department of Mathematics, Indian Institute of Technology Roorkee, India. Born on August 15, 1958, she pursued B.Sc Hons and M.Sc Hons. School from Centre for Advanced Studies, Panjab University, Chandigarh. An M.Phil Gold Medalist, she earned her PhD from IIT Roorkee in 1988, assisted by UGC Scholarship throughout. She carried out Post-Doctoral Research at Loughborough University, UK during 1993-94, under an International Post Doctorate Bursary funded by Commission of European Communities, Brussels. She was awarded the Khosla Research Award in 1991; UGC Career Award in 2002; Starred Performer of IIT - Roorkee Faculty continuously from 2001 to 2005; best paper, Railway Bulletin of Indian Railways, 2005; special facilitation in memory of late Prof. M. C. Puri, 2007. She has co-authored a book entitled "Optimization Techniques" by New Age Publishers New Delhi in 2009 with an International edition by New Age Science, UK.

Eleven students have been awarded $\mathrm{PhD}$ under her supervision and six are in progress. She has 80 research publications in refereed International Journals and 60 research papers in International / National Conferences. She is on the editorial board of a number of International and National Journals. She is a Senior Member of Operations Research Society of India, IEEE, Computer Society of India, Indian Mathematical Society and Indian Society of Industrial Mathematics. She is on the Expert Panel of the Department of Science and Technology, Govt. of India. She is the Executive Editor of International Journal of Swarm Intelligence, Inderscience. She is the Founder President of Soft Computing Research Society, India and the secretary of Forum of Interdisciplinary Mathematics.

Her areas of specialization are numerical optimization and their applications to engineering, science and industry. Currently her research interests are Nature Inspired Optimization Techniques, particularly, Genetic Algorithms, Memetic Algorithms, Particle Swarm Optimization, Artificial Bee Colony, Biogeographical Based Optimization, Glowworm Optimization, and their applications to solve real life problems.

How to cite this paper: Amarjeet Singh, Kusum Deep,"Real Coded Genetic Algorithm Operators Embedded in Gravitational Search Algorithm for Continuous Optimization", International Journal of Intelligent Systems and Applications (IJISA), vol.7, no.12, pp.1-22, 2015. DOI: 10.5815/ijisa.2015.12.01 